\title{
Some Innovative Solutions for Dealing with Problematic Soils in Infrastructure Developments
}

\author{
Mohamed A. Shahin \\ Curtin University, Department of Civil Engineering \\ GPO BOX U1987, Perth, WA 6845, Australia \\ m.shahin@curtin.edu.au
}

\begin{abstract}
Problematic soils (e.g. collapsible, soft, reactive) pose significant challenges to the geotechnical communities due to their low bearing capacity and high compressibility, causing distress and damage to many infrastructure developments including foundations, retaining walls, pavements, etc. The constraints on construction time and environmental and safety issues, as well as maintenance costs and expected lifetime of structures have continued to demand unfailing innovation in construction encircling problematic soils. Although the risks associated with problematic soils have been long recognised, problems associated with such soils and corresponding financial losses are increasing in many places around the world. Numerous solutions have thus been proposed for construction on problematic soils including replacement of the entire problematic materials, soil stabilisation by chemical additives (e.g. cement) and use of pile foundations. However, most existing solutions have either environmental serious concerns (e.g. chemical additives) or costly (e.g. pile foundations). In this paper, some innovative and promising solutions for dealing with problematic soils are proposed and presented, and their controlling parameters, efficiency and limitations are demonstrated and discussed.
\end{abstract}

Keywords: Problematic soils, ground improvement, soil stabilisation, infrastructure developments, biocementation, granular pile anchor foundations, prefabricated vertical drains, numerical modeling.

\section{Introduction}

The current rapid growth of population caused an increasing demand for new infrastructures, which are limited by the presence of poor soil conditions. In order to utilise unstable (problematic) soils for infrastructure developments, they have to be either improved or replaced with more suitable soil deposits. The goal of soil improvement is to transform the unstable soils, which usually have low bearing capacity and high compressibility, into stable foundations. With roughly 40,000 projects that require soil improvement world-wide each year, adding up to AUD\$6 billion [1], geotechnical engineers are challenged in providing workable ground for most civil engineering structures. Existing technologies for soil improvement include [2]: chemical stabilisation, strengthening by drainage, densification by mechanical compaction or vibration, the use of pile foundations, reinforcement with steel or geosynthetics and the use of electro-osmosis. Among these methods, chemical stabilisation by grouts is widely employed, where the mineralogical structure of soil is altered by chemical additives (e.g. cement and lime) to improve the physical and mechanical engineering properties of soils. However, most chemical grouts increase the $\mathrm{pH}$ of groundwater to highly alkaline levels, hinder groundwater flow and significantly reduce soil permeability. More importantly, chemical grouts can cause serious environmental problems and contribute to ecosystem disturbance. For example, one of the most commonly used chemical grout nowadays (i.e. Portland cement) is a major source of green-house gas emission causing global warming. Li et al. [3] reported that cement production is estimated to account for $7 \%$ of global carbon dioxide emission. Furthermore, acrylamide grout was associated with five cases of water poisoning in Japan in 1974, resulting in the ban of nearly all chemical grouts [4]. More recently, initiatives in certain countries, such as the USA, have proposed to ban most synthetic grouting materials [1] both because of their toxicity and due to a desire to reduce cement use as this is a major contributor to global anthropogenic carbon dioxide emissions. Therefore, there is an immense need for alternative environmentally-friendly, sustainable and cost-effective technologies that can fulfil the increasing demand for soil improvement.

This paper proposes three different "innovative" solutions for dealing with problematic soils in infrastructure developments. Each proposed solution will be described in some detail and its corresponding affecting parameters will be investigated and discussed. The first solution introduces a newly emerging biological cementation technique, through a 
process known as microbial induced calcite precipitation (MICP), for stabilisation of collapsible soils. This technique utilizes the metabolic pathway of earth-based bacteria to form calcite precipitation inside the soil matrix, leading to increased soil strength and stiffness while maintaining adequate soil permeability. The second solution involves a promising foundation system called granular pile anchor foundation (GPAF) that can be used to mitigate the serious consequences of volumetric changes of reactive soils, both during expansion and shrinkage. The ability of the GPAF system to resist the forces induced by the soil movement due to soil moisture variation, and the impact of this resistance on the stability of superstructure, will also be investigated. The third solution proposes a new approach for design of soft clay stabilisation by prefabricated vertical drains, by allowing the true nature of soil spatial (inherent) variability to be appropriately simulated and considered. This approach involves using statistical methods that integrate the random field theory and finite element modeling into a Monte Carlo framework.

\section{Bio-cementation for Collapsible Soils}

In this section, a new emerging and promising soil stabilisation technique that has recently gained interest by many researchers and geo-engineers is introduced and presented. The technique is called bio-cementation using microbial-induced calcite precipitation (MICP), which has proved its sustainability and capability to alter and improve most soil engineering properties. This technology utilises the metabolic pathway of ureolytic bacteria to form calcite precipitation throughout the soil matrix, resulting in increased soil strength and stiffness while maintaining adequate permeability. Bio-cementation using MICP involves injecting aerobically cultivated ureolytic bacteria, i.e. Bacillus pasteurii (also known as Sporosarcina pasteurii), into soil with calcium-rich solution and highly active urease enzyme to catalyse the hydrolysis of urea. From this reaction, ammonium and carbonate are produced, and the process can be described as follows [5]:

- Urea is hydrolysed by microbial urease to form ammonium and carbonate ions:

$$
\mathrm{CO}\left(\mathrm{NH}_{2}\right)_{2}+2 \mathrm{H}_{2} \mathrm{O} \rightarrow 2 \mathrm{NH}_{4}^{+}+\mathrm{CO}_{3}^{2-}
$$

- In the presence of calcium source (in most cases calcium chloride), the produced carbonate ions react with the calcium ions to produce precipitated calcium carbonate $\left(\mathrm{CaCO}_{3}\right)$ crystals:

$$
\mathrm{Ca}^{2+}+\mathrm{CO}_{3}^{2-} \rightarrow \mathrm{CaCO}_{3}
$$

The precipitated calcite bridges the adjacent soil particles together, leading to increased soil strength and forming cemented soil that is very similar to that of calcareous rocks [6]. The rate of calcite precipitation can be governed by many factors such as the amount of $\mathrm{pH}$, concentration of calcium ions and presence of nucleation sites in the soil matrix [7]. The MICP process simulates the natural digenesis from sand to sandstone, only within a short time instead of million years.

This section presents some results of the author and his co-workers for investigating the practicality of MICP towards its usage for ground improvement by examining some physical and environmental parameters which may impact the effectiveness of this technique in terms of unconfined compressive strength. The influence of soil initial density, degree of temperature at which bio-cementation occurs, initial $\mathrm{pH}$ of soil and degree of saturation of treated soils, will be examined. The possibility of using the seawater as a calcium source for bio-cementation will also be investigated, which can significantly reduce the cost of bio-cementation treatment. MICP is successful for soils that have pore sizes within the range of injected bacterial solutions [8] and is thus more suitable for pure collapsible (loose and erodible) silica or carbonate sands. However, the feasibility of treating sand with fines (clayey sand) and corresponding maximum cementation strength will also be assessed.

\subsection{Experimental Programme}

Industrial pure silica sand, which has the grain size distribution shown in Figure 1, was used for the experimental programme presented in this study. The sand used was classified as poorly graded according to the Unified Soil Classification System with a predominant particle size of $0.425 \mathrm{~mm}$. This sand was used as it exhibits undesirable engineering properties for most geotechnical engineering applications. 


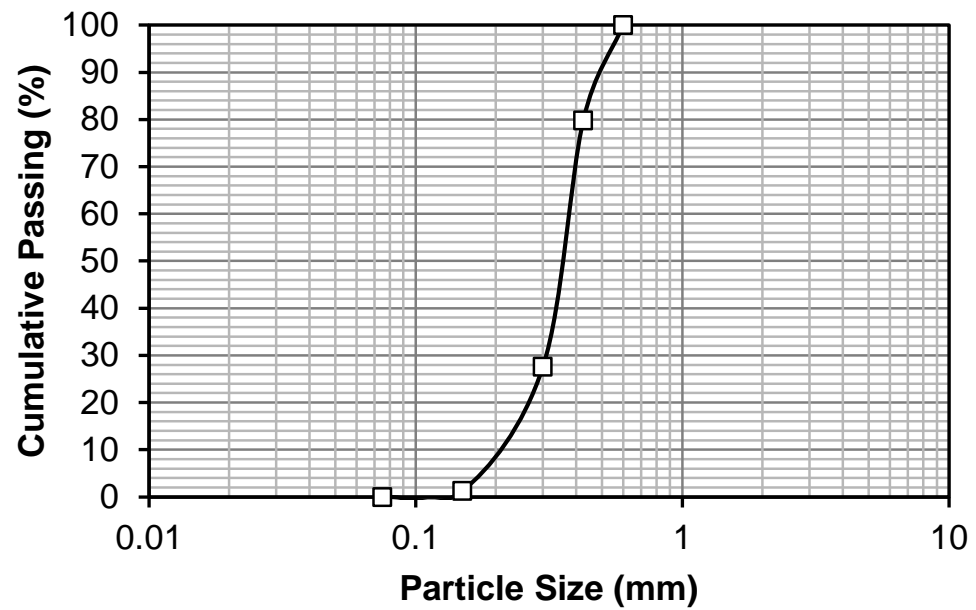

Fig. 1: Particle size distribution curve of sand used in the experimental programme.

Before carrying out the geotechnical engineering tests, specimens of the above sand were treated and prepared. Highly ureolytic bacteria were cultivated aerobically in the laboratory as follows. The urease active strain used in the current study was Bacillus sphaericus (MCP-11) (DSM 23526, available from DSMZ, Germany). The liquid medium was prepared using a ratio of $20 \mathrm{gm}$ per litre of yeast extract added to deionised water. The following substances were added to the media: 0.17 $\mathrm{M}$ of Ammonium Sulphate, $\left[\mathrm{NH}_{4}\right] 2 \mathrm{SO}_{4}$ and $0.1 \mathrm{mM}$ of Nickel Chloride, $\mathrm{NiCl}_{2}$. The $\mathrm{pH}$ adjustment was made using sodium hydroxide, $\mathrm{NaOH}$, to obtain a basicity of 9.25 . Before inoculation, the growth medium was sterilised by supplying an inoculum of approximately $2-5 \%$ of pure bacteria culture into the medium to initiate microbial growth, then was incubated for an extended period of time. After 24 hours of cultivation at $28^{\circ} \mathrm{C}$, the bacteria culture was collected and stored at $4^{\circ} \mathrm{C}$ prior to use. The optical density (OD600) of the culture varied between 0.6-1.0, and the urease activity was approximately $5 \mathrm{U} / \mathrm{mL}(1 \mathrm{U}=1 \mu \mathrm{mol}$ urea hydrolysed per $\min )$.

Reagent solutions containing a mixture of $1 \mathrm{M}$ calcium chloride $\mathrm{CaCl}_{2}(111 \mathrm{~g} / \mathrm{L})$ and $1 \mathrm{M}$ urea $\mathrm{CO}\left(\mathrm{NH}_{2}\right)_{2}(60 \mathrm{~g} / \mathrm{L})$, were prepared and flushed through the sand specimens at an injection flow rate of $1 \mathrm{~L} /$ hour. Throughout the flushing applications, fully saturated condition (i.e. 100\% degree of saturation) was maintained using a pressurized vacuum to remove the previously supplied solution, leaving the next solution application as residual. For the seawater experiments, the cementation solution was prepared by adding $10 \mathrm{mM}$ urea $(0.6 \mathrm{~g} / \mathrm{L})$ into artificial seawater, which consisted of different concentrations of salts $(\mathrm{g} / \mathrm{L})$ including: $\mathrm{NaCl}$ (23.9), $\mathrm{Na}_{2} \mathrm{SO} 4$ (4.0), $\mathrm{CaCl}_{2} .2 \mathrm{H}_{2} \mathrm{O}$ (1.5), $\mathrm{MgCl}_{2} .6 \mathrm{H}_{2} \mathrm{O}$ (10.8), $\mathrm{KCl}(0.7)$, $\mathrm{NaHCO} 3$ (0.2), $\mathrm{KBr}(0.1)$ and $\mathrm{H}_{3} \mathrm{BO}_{3}(0.03)$.

\subsection{Soil Initial Density}

Preparation of sand specimens of different densities (compacted and un-compacted) was made by packing the sand into polyvinyl chloride (PVC) columns of $150 \mathrm{~mm}$ in height and $50 \mathrm{~mm}$ inner diameter. The average dry density of the compacted samples was $16 \mathrm{kN} / \mathrm{m}^{3}$, whereas it was $14.1 \mathrm{kN} / \mathrm{m}^{3}$ for the un-compacted samples. Figure 2 shows a comparison between the compacted and un-compacted bio-treated soils in terms of unconfined compressive strength (UCS). It can be seen that the initial soil density has a significant impact on the effectiveness of bio-cementation. For similar produced calcite content, the compacted (high initial density) samples were found to give greater UCS values than those of the un-compacted (low initial density) samples. This is because the sand particles in the compacted samples are closer together than the uncompacted samples; hence, the $\mathrm{CaCO}_{3}$ crystals are formed over a shorter distance to bridge the sand particles. 


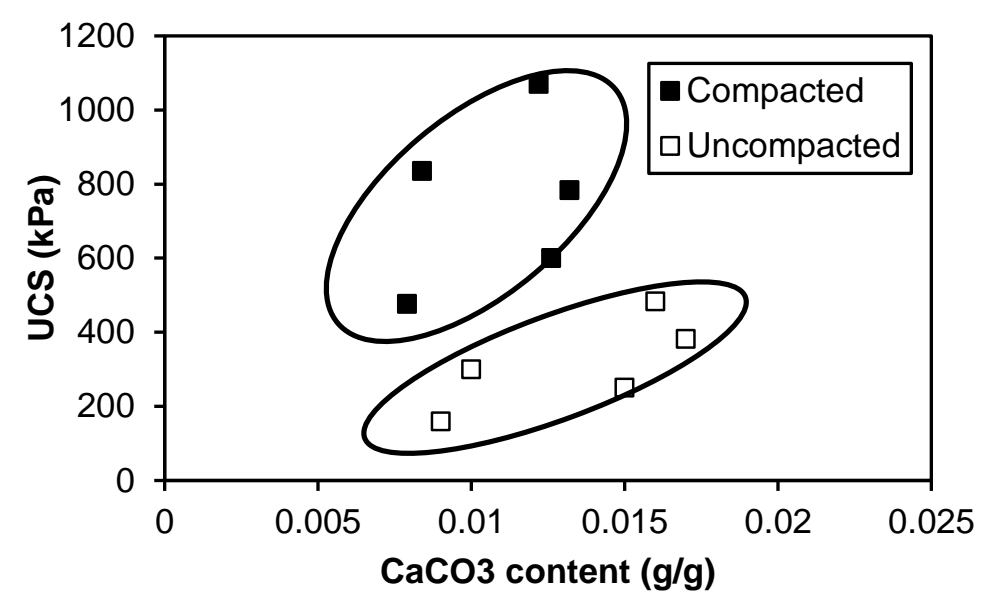

Fig. 2: Comparison between compacted and uncompacted strength of treated samples [9].

\subsection{Degree of Temperature}

Figure 3 shows the results of obtained UCS and $\mathrm{CaCO}_{3}$ content for samples treated at the room temperature $\left(25^{\circ} \mathrm{C}\right)$ and at higher temperature $\left(50^{\circ} \mathrm{C}\right)$. It can be seen that although about 3 times more $\mathrm{CaCO}_{3}$ crystals were formed at higher temperature of $50^{\circ} \mathrm{C}$, the treated samples exhibited about $60 \%$ less strength than the samples treated at the room temperature. This decreased strength (with even more amount of $\mathrm{CaCO}_{3}$ ) at high temperature is interesting in terms of both the scientific and applied aspects. In order to further investigate the impact of temperature on the crystals formation of treated samples, scanning electron microscopy analysis was carried out and its results showed that the amount of $\mathrm{CaCO}_{3}$ precipitated at $50^{\circ} \mathrm{C}$ is much higher than that formed at low temperature of $25^{\circ} \mathrm{C}$, as the high temperature promoted an increased urease activity. It was also observed that the crystals produced at high temperature are relatively small in size (about 2-5 $\mu$ m in diameter) and fully cover the surface of the sand grains, where the crystals cannot contribute to the strength development. On the other hand, the samples treated at the room temperature produced smaller amount of crystals but of larger size of 15-20 $\mu \mathrm{m}$, which benefited the gap filling between the adjacent sand grains; hence, efficiently contributed to the strength development. This finding implies that it is not the amount of produced $\mathrm{CaCO}_{3}$ content that governs the strength of bio-treated soils but rather the way the produced $\mathrm{CaCO}_{3}$ crystals are formed. It should be noted that there are a number of other factors that may affect the crystals formation, such as the degree of saturation, which will be discussed later. Further work was carried out for samples treated at $4^{\circ} \mathrm{C}$ (results not shown) and it was noted that the strength improvement as per the amount of crystals produced was higher at $25^{\circ} \mathrm{C}$ compared to that produced at low temperature of $4^{\circ} \mathrm{C}$. In comparison it was derived that the crystals formed at the highest temperature of $50^{\circ} \mathrm{C}$ was the least efficient to gain strength improvement.

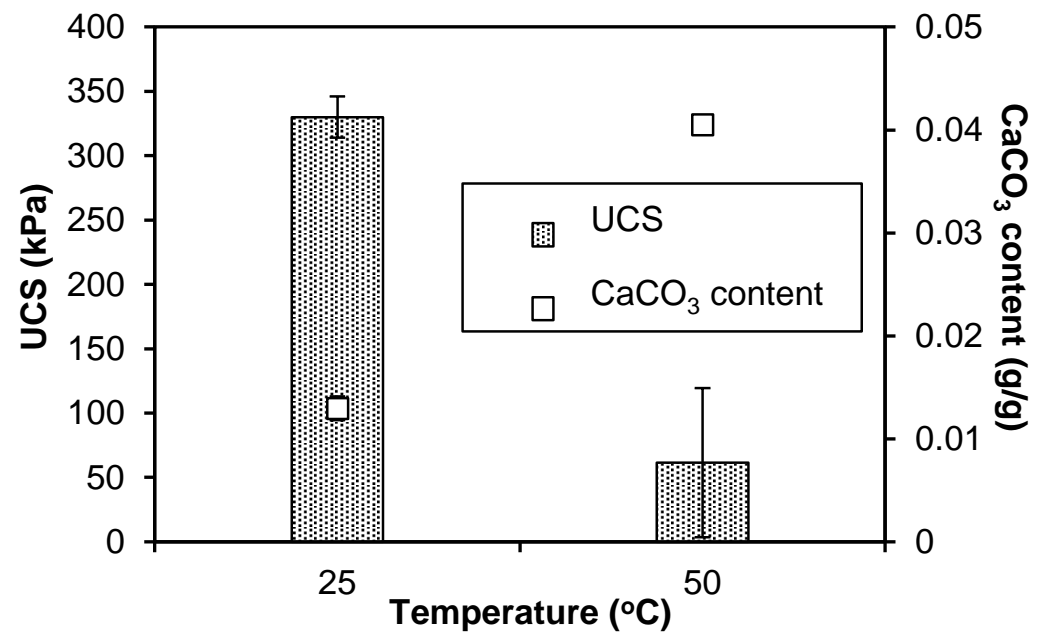

Fig. 3: UCS and $\mathrm{CaCO}_{3}$ content of samples treated at different temperatures [9]. 


\subsection{Initial pH of soil}

As shown in Figure 4, the initial $\mathrm{pH}$ of soil has a significant impact on the final compressive strength of bio-treated samples. It can be seen that both the acidity and alkalinity conditions have negative effects on the treated soil, resulting in decreased soil strength even in the presence of high content of $\mathrm{CaCO}_{3}$ crystals. As mentioned by many researchers [e.g. 10], the $\mathrm{pH}$ value can influence the bacteria transport and adhesion, which is an essential factor for achieving homogeneously improved strength. The initial $\mathrm{pH}$ can also affect the formation of crystals as the solubility of $\mathrm{CaCO}_{3}$ varies according to the $\mathrm{pH}$ value. This may be due to the urea hydrolysis reaction, which continuously produces a mixture of $\mathrm{NH}_{3} / \mathrm{NH}_{4}{ }^{+} / \mathrm{CO}_{3}{ }^{2-} / \mathrm{HCO}_{3}{ }^{-}$ solution with a strong $\mathrm{pH}$ buffer capability.

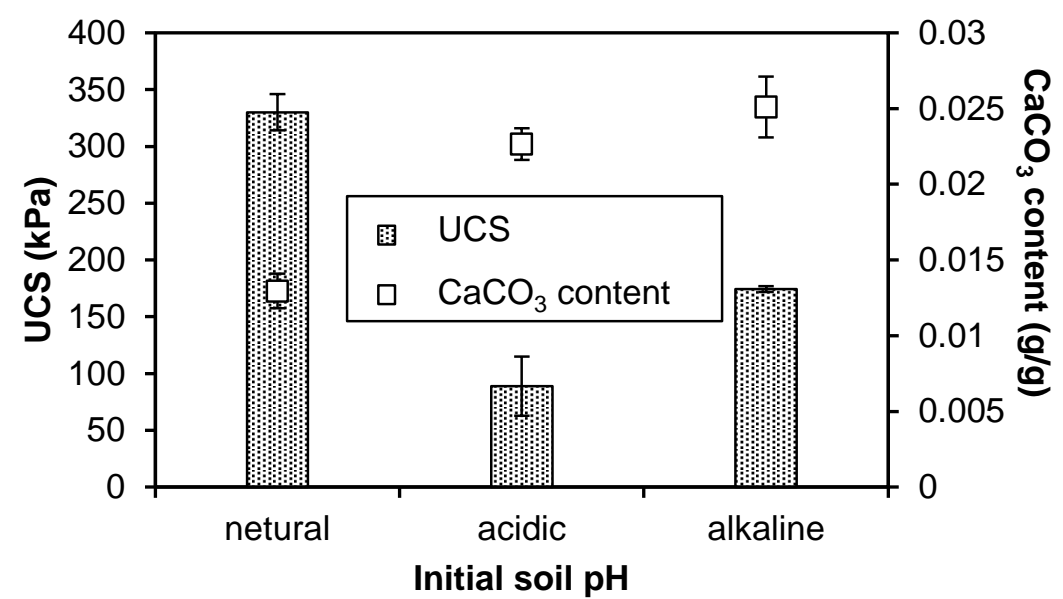

Fig. 4: UCS and $\mathrm{CaCO}_{3}$ content of sand treated with different initial $\mathrm{pH}$ values [9].

\subsection{Degree of Saturation}

Reagent solutions containing calcium chloride, $\mathrm{CaCl}_{2}$, and urea, $\mathrm{CO}\left(\mathrm{NH}_{2}\right)_{2}$, were prepared and flushed through the sand specimens at various amounts of water, to provide the desired degree of saturation within the soil matrix. Throughout the flushing applications, a specified degree of saturation was maintained using a pressurized vacuum to remove the previously supplied solution, leaving the next solution application as residual. This was achieved using the following three steps [11]: (1) alternating injection of equal volumes of bacterial suspension and cementation solution with an inflow rate of about $1 \mathrm{~L}$ /hour; (2) curing for 12 hours at $25 \pm 1^{\circ} \mathrm{C}$ to allow the bacterial fixation process to complete; and (3) percolation of cementation solution with the same flow rate followed by another curing period of 12 hours at $25 \pm 1^{\circ} \mathrm{C}$. Figure 5 shows the UCS results of bio-cemented samples treated at different degrees of saturation of $20 \%, 40 \%, 80 \%$ and $100 \%$. It can be seen that at any degree of saturation there is an increase in the soil compressive strength with the increase in the produced calcite content, at any degree of saturation. It can also be seen that at the same calcite content, the soil treated at lower degree of saturation exhibits significantly higher values of shear strength. This can be attributed to the effectiveness of the calcite crystals formation within the soil matrix, which is clearly demonstrated by the images taken from the scanning electron microscopy shown in Fig. 6 for soil treated at fully and partially saturated conditions. For fully saturated treatment condition (Figure 6a), the produced calcite is not fully formed at the inter-particle contact points of the soil grains but floccules either on the grain surface or suspends in the pore space between the soil grains. These nucleation sites are ineffective and the calcite formation provided no significant soil strength improvement. In the case of partially saturated treatment condition (Figure 6b), the calcite formation effectively coats over the soil particles and predominantly occurs at the effective areas of granular contact points. This calcite formation provides rationale to the significant reduction in the $\mathrm{CaCO}_{3}$ content, obtaining similar strength to that witnessed for the saturated condition. The above results indicate that the mechanical strength of biotreated soils is mainly due to the effectiveness of calcite crystals formation rather than the total amount of produced calcite. Given the verified effectiveness of the bio-cementation process in increasing the strength of soil in a diverse range of in-situ saturation conditions, bio-cementation by MICP may be used as a viable solution to reduce the potential of granular soils to liquefy through providing the soil with greater resistance against the adverse deformations associated with the earthquakes induced loadings. 


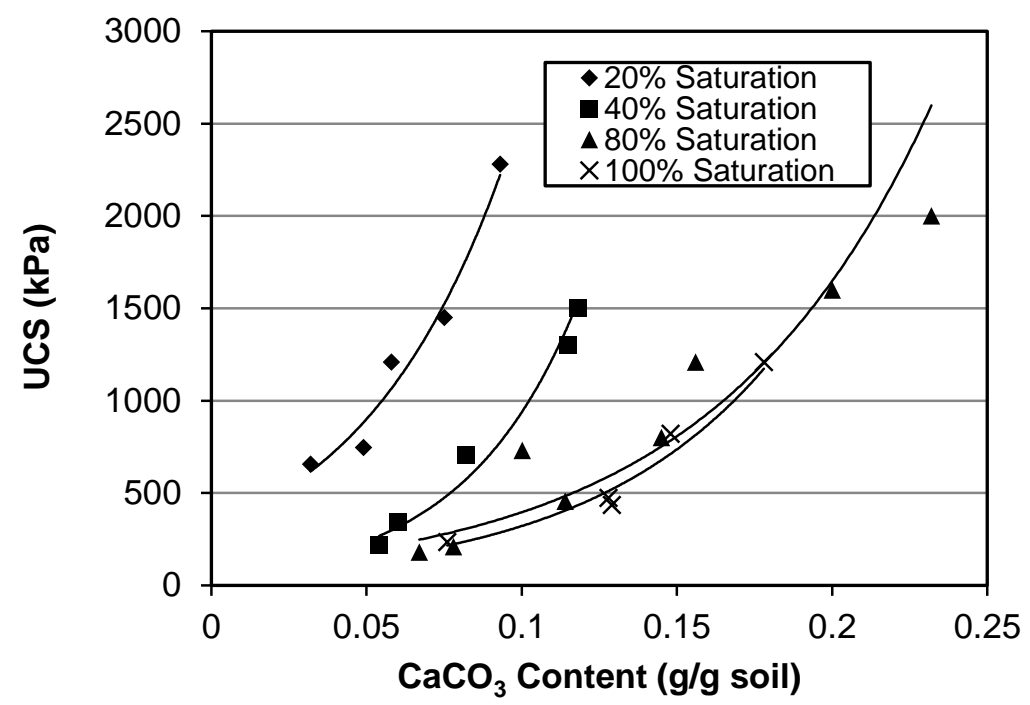

Fig. 5: UCS results of bio-cemented soil at different degrees of saturation [12].

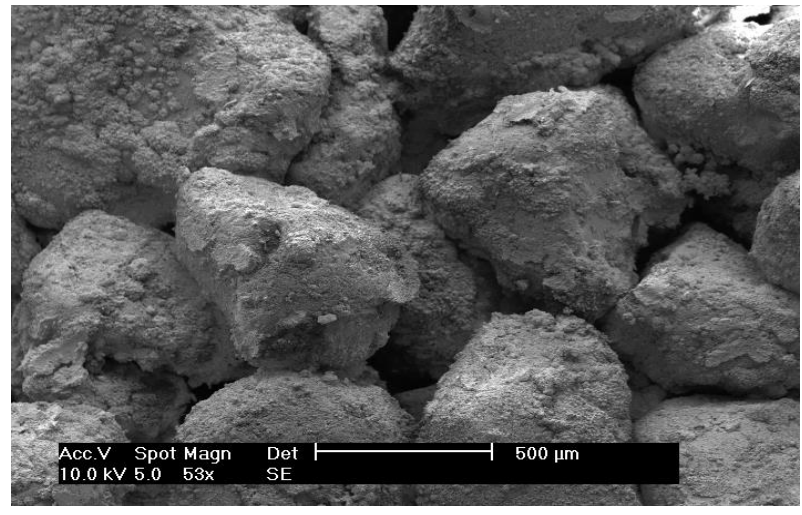

(a) Soil treated at fully saturated condition

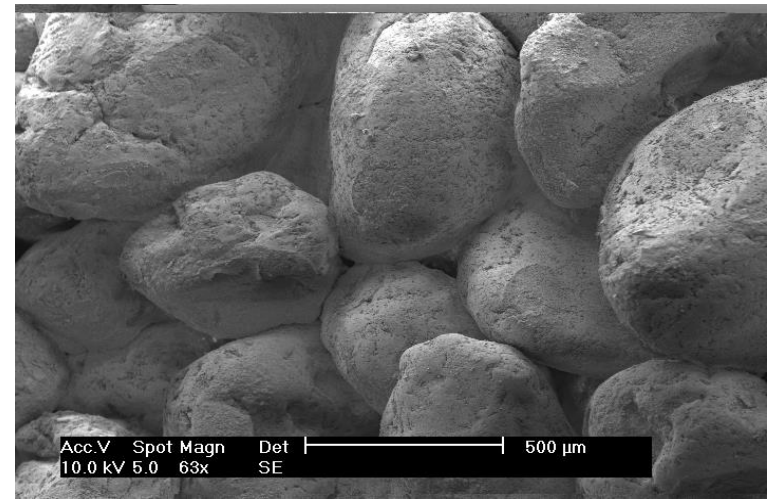

(b) Soil treated at partially saturated condition

Fig. 6: UCS results of bio-cemented soil at different degrees of saturation [12].

\subsection{Use of Seawater as Calcium Resource}

The cost of the MICP process including bacterial cultivation, chemical usage, equipment and labour may prevent the progress of further commercial development for this emerging ground improvement technique. Consequently, an attempt was made to exploit the potential benefit of using the seawater to reduce the cost of bio-cementation bringing it closer to be commercially acceptable ground improvement alternative. Some results of using the seawater in MICP treatment are shown in Figure 7, which clearly demonstrate the feasibility of using the seawater as a chemical reagent for bio-cementation. It can be seen that the compressive strength of soil is exponentially increased with the increase in the precipitated carbonate content, which is in line with the previous presented results. However, for the same amount of precipitated carbonate, the compressive strength of soil treated with seawater is higher than that of the soil treated using the traditional cementation solution method. This is in line with the previous reported observations and is due to the fact that higher concentration of urea and calcium chloride usually generates a significant amount of calcite; however, the efficiency of the produced calcite is normally lower compared to the formation of calcite at lower concentration produced from using the seawater as a calcium resource. However, it should be noted that the use of seawater as a relatively dilute calcium solution requires many subsequent treatment (probably 60 or 80 flushes) to get similar UCS values of the traditional cementation solution of urea and calcium chloride; however, each treatment can be completed within a shorter period of time (e.g. 6 hours) compared to 24 hours for a single treatment using the traditional cementation solution. 


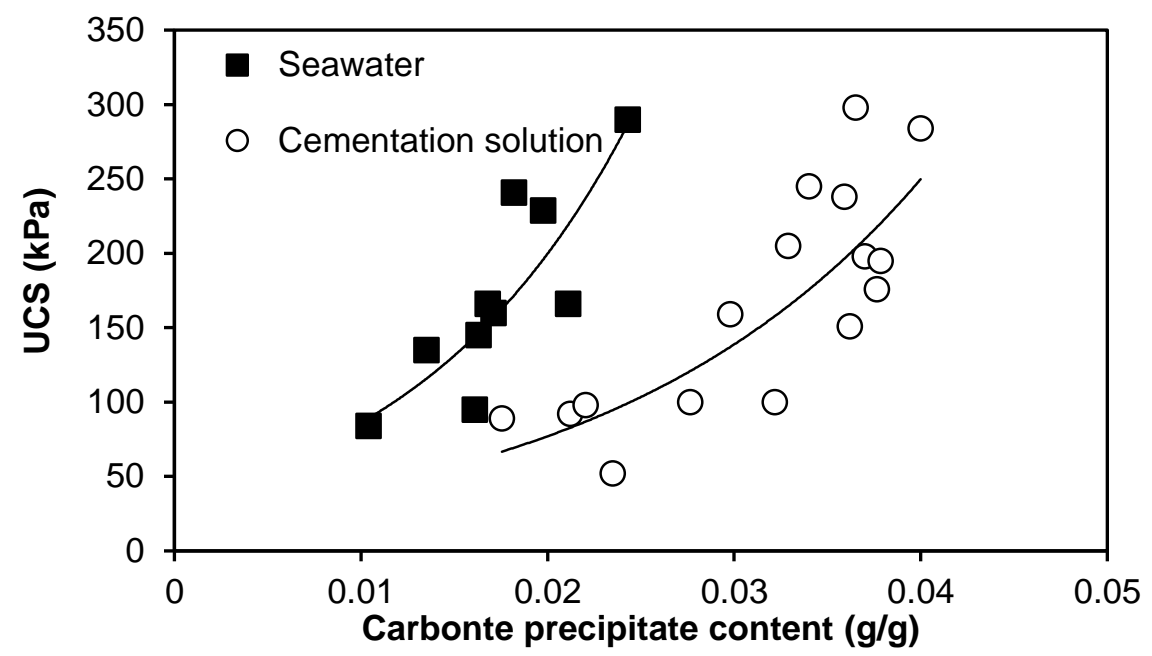

Fig. 7: Bio-cemented soil treated with seawater as the sole source of calcium [13].

\subsection{Percentage of Fines}

Sand specimens of $50 \mathrm{~mm}$ in dimeter and $150 \mathrm{~mm}$ in height that contain clay fines were treated using the treatment procedure explained earlier and the results are shown in Figure 8. In Figure 8(a) the UCS values of bio-treated sand containing $5 \%$ clay are comparted with the bio-treated sand alone. It can be seen that the UCS increases exponentially with the increase in the calcite content, for both bio-treated sand alone and sand contains 5\% fines; however, there is a slight increase in the UCS values of bio-treated sand containing 5\% clay compared to those of the bio-treated sand alone. This may be attributed to the increased cohesion of the sand with fines, and it may also be due to the increase in the contact surface area provided by the clay fine particles, which may facilitate the bridging formation between the sand particles via the calcite crystals.
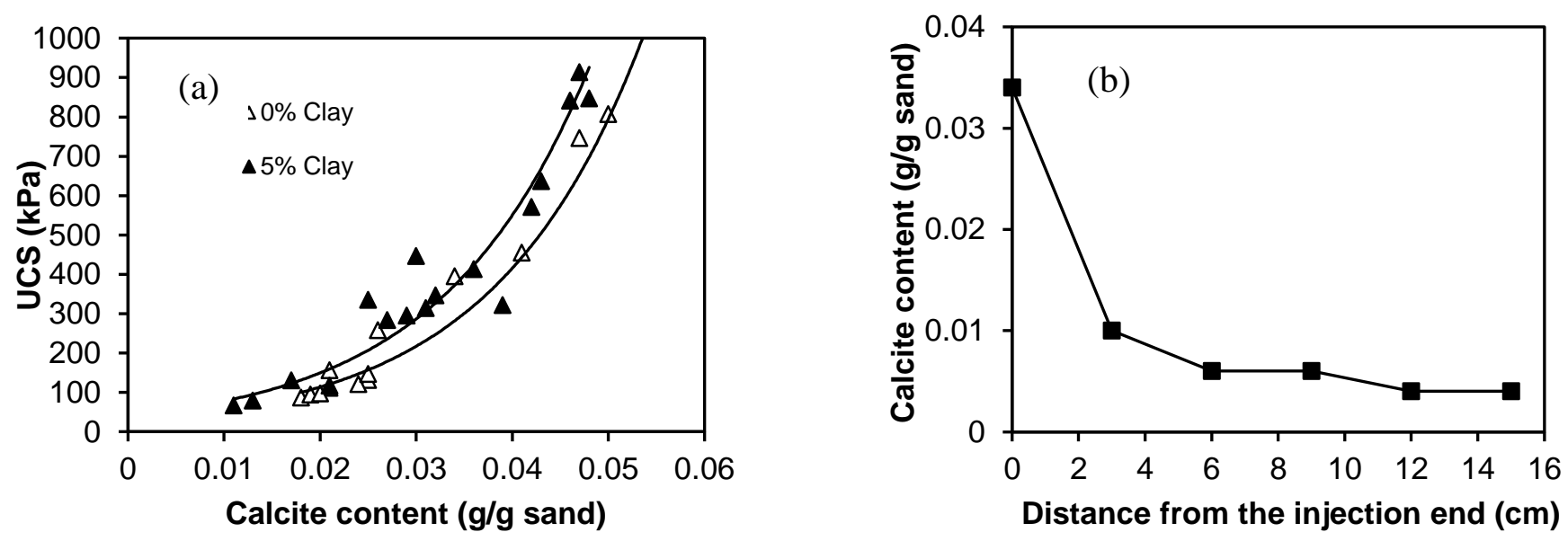

Fig. 8: Impact of adding fines on bio-cementation of sand: (a) Calcite content versus UCS for bio-treated sand containing 0\% and 5\% fines; and (b) Distribution of calcite content along bio-treated sand column containing 10\% fines [14].

In Figure 8(b), the results of bio-treated sand containing 10\% clay fines indicate that the injection end blocking (excessive cementation) and minor calcite precipitation inside the treated sand columns were observed and this was occurred after three flushes of treatment. Further treatment became difficult to conduct due to the serious clogging. This phenomenon of clogging is possibly attributed to the high amount of urea hydrolysed; hence, the calcite formed at the injection end is determined by the presence of urease activity and duration over which the cementation solution is exposed to the clogging area. The sand samples containing $10 \%$ clay content, which have smaller pores, acted as a filter to the bacteria and resulted in the accumulation of the bacterial cells (also urease activity) around the injection end. The accumulated urease activity associated with low infiltration rate of cementation solution resulted in excessive bio-cementation occurring at the injection end rather than distributed uniformly along the sand columns. This indicates that bio-cementation treatment using the 
injection method may not be applicable to soils that contain more than 5\% clay due to the immediate bio-clogging at the injection end (bacterial cells blocked the pores) and thus alternative treatment processes are necessary to fine-grained soils or coarse-grained soils containing fines.

\section{Granular Pile Anchor Foundations for Reactive Soils}

Reactive soils are clays that swell and shrink with changing moisture content, and pose significant challenges to the geotechnical community due to their potential to cause ground movement, thereby causing distress to foundations of lowstorey buildings and cracking to light-weight structures [15]. Although the risk associated with foundations build on reactive soils have been long recognized, especially in developed countries, problems associated with such soils are ever increasing. For example, the American Society of Civil Engineers estimated that about one quarter of all homes in the US have experienced some damage from reactive soils; the financial losses incurred by property owners exceed those caused by natural disasters such as earthquakes, floods, hurricanes and tornadoes combined (http://geology.com/articles/reactivesoil.html). In Australia, despite the stringent regulatory requirements, most lightweight structures built on reactive soils experience some distortional damage during their lives [16].

There are numerous solutions proposed in the literature for construction on reactive soils, including replacement of the entire reactive material, soil stabilization using a variety of chemical additives (e.g. lime or cement), use of pile foundations or drilled/friction piers. One innovative and promising special foundation solution that has not been yet used in practice is the granular pile-anchor foundation system (GPAF). This foundation system was firstly proposed by Phanikumar and Ramachandra Rao [17] and investigated further by other researchers during the last decade via laboratory and limited field trials [see 18, 19]; however, the technique is yet to be applied in practice primarily due to the ambiguity related to its performance. In an attempt to further understand the behaviour of this promising foundation system and to determine its controlling parameters, the technique was further investigated by the author and his co-workers, using the finite element numerical modelling, and some results are presented below.

\subsection{Concept of GPAF System}

Figure 9 shows a schematic diagram of a typical GPAF system, which consists of a pile of granular material compacted into a borehole that is made into the reactive soil, and the concrete footing is then constructed above the granular pile. In order to prevent upward movement of the footing during heave of the reactive soil, the footing has to transfer the uplift pressure down to the granular pile via a steel anchor that is casted with the concrete footing. Accordingly, the uplift resistance is ultimately mobilized as shearing stress along the granular pile interface. The force in the pile anchor is transmitted to this interface via a base plate that is rigidly connected to the anchor.

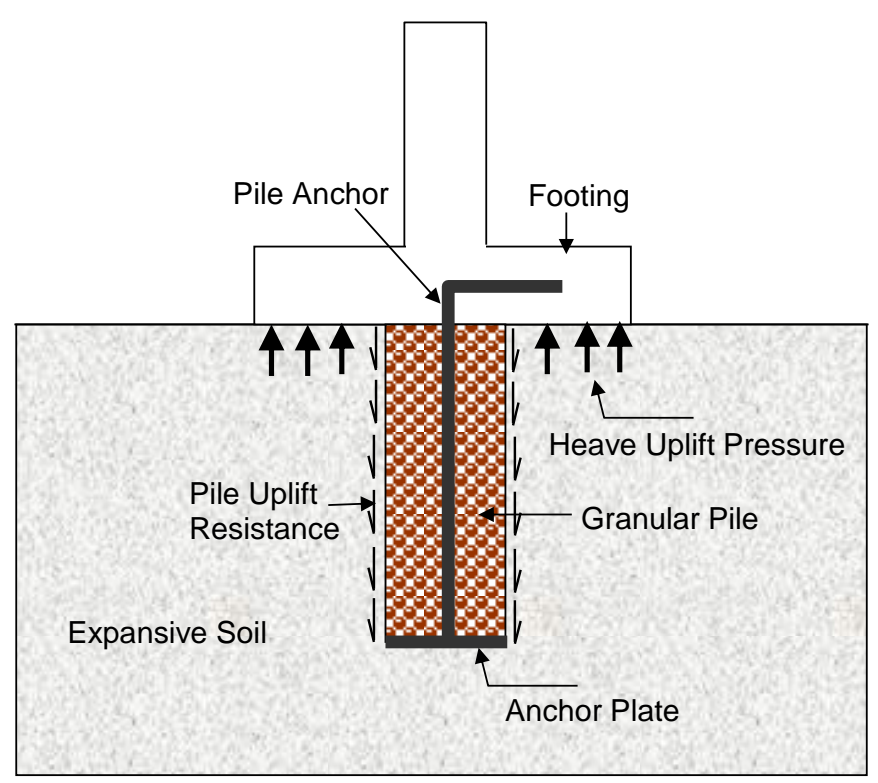

Fig. 9: Schematic diagram of a typical GPAF system [20]. 
According to the arrangement of the anchorage system of the GPAF, between the footing and granular pile, the latter cannot only reinforce the ground (as in the case of soft clay and loose sand) but can also effectively resist the uplift forces from reactive soils. As can be shown in Figure 9, the uplift resistance of the GPAF system is a function of the self-weight of the pile-footing assembly, interface shear strength, surface area of the granular pile and normal stress developed during the expansion of the soil surrounding the pile.

\subsection{Numerical Modelling Analysis of GPAF System}

The behavior of a single footing reinforced with the GPAF system was investigated using the numerical modelling via the finite element method (FEM) and was analyzed as an axisymmetric problem using PLAXIS 2D software [21]. The 2D axisymmetric model is presented in Figure 10, which consists of 1000, 15 node triangular elements. The footing diameter was fixed at $2.0 \mathrm{~m}$ and the granular pile length was fixed at $3.0 \mathrm{~m}$. The diameter of the granular pile was varied at $0.25,0.5$, 0.75 and $1.0 \mathrm{~m}$.

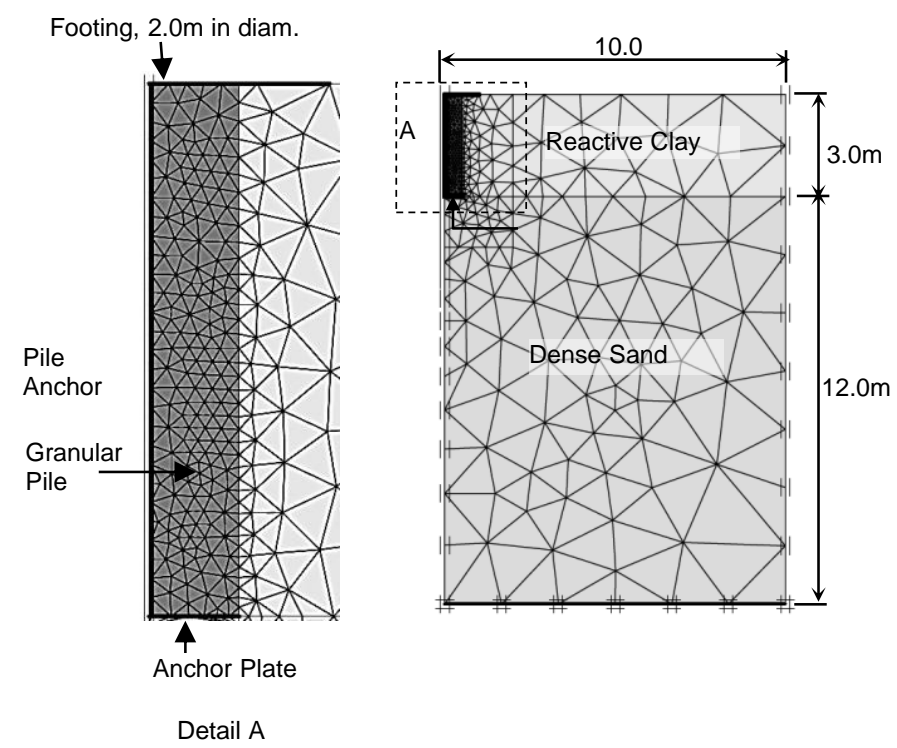

Fig. 10: Finite element model for a typical GPAF system [20].

The idealized ground profile consisted of $3.0 \mathrm{~m}$ of reactive clay overlying dense sand. To improve the accuracy of the analysis, the model was strategically refined around the footing and the granular pile, and to minimize the boundary effect, the pile and boundaries were located farther from the area of interest. The concrete footing was modeled using a Mindlin's plate element of an elastic modulus of $35 \mathrm{GPa}$, thickness of $0.6 \mathrm{~m}$ and Poisson's ratio of 0.15 . The pile anchor was modeled as an elastic embedded pile of $30 \mathrm{~mm}$ diameter and Young's modulus of $200 \mathrm{GPa}$. The reactive clay, the underlying dense sand and granular pile material were modeled using the hardening soil model (HS) in PLAXIS [22]. The HS model is a nonlinear elastic-plastic formulation which adopts multiple yield loci as a function of plastic shear strain and a cap to allow for volumetric hardening. The non-linear stress strain relationship is represented by a hyperbolic formula, with primary loading governed by a secant deformation modulus $\left(E_{50}\right)$ at $50 \%$ of the material strength. Loading and unloading of the current yield surface are elastic (defined by a separate modulus, $E_{u r}$ ) with failure governed by the Mohr-Coulomb failure criterion. Both $E_{50}$ and $E_{u r}$ evolve with the minor effective stress, $\sigma_{3}^{\prime}$, according to the following formula:

$$
E_{50}=E_{50}^{r e f}\left(\frac{c \cos \varphi-\sigma_{3}^{\prime} \sin \varphi}{c \cos \varphi+p_{r e f} \sin \varphi}\right)^{m}
$$

where; $c$ is the soil cohesion, $\phi$ is the peak friction angle, $m$ is the exponent that controls dependency of the stiffness on stress and $p_{r e f}$ is the reference stress corresponding to $E_{50}^{r e f}$. A summary of the parameters used for all soils are presented 
in Table 1. The properties of clay were those evolving after the wetting event and during expansion (strictly speaking, the strength of a reactive soil degrades during expansion but this was not modeled in this study). The clay layer was assumed to behave in an undrained manner during expansion. Heave and shrinkage of the reactive clay were modeled by applying a volumetric strain to the reactive clay layer. In reality, the rate at which the reactive clay would normally expand depends on the location from the source of moisture and magnitude of overburden pressure. However, for simplicity, in the analysis presented herein, the volumetric strain was applied uniformly across the full thickness of the clay layer.

Table 1: Material properties used in the finite element analyses.

\begin{tabular}{|c|c|c|c|c|c|c|c|c|c|c|}
\hline Soil Layer & $\begin{array}{c}\gamma_{d} \\
\left(\mathrm{kN} / \mathrm{m}^{3}\right)\end{array}$ & $\begin{array}{c}E_{50(\mathrm{ref})} \\
(\mathrm{MPa})\end{array}$ & $\begin{array}{c}E_{\text {oed }(\mathrm{ref})} \\
(\mathrm{MPa})\end{array}$ & $\begin{array}{c}E_{\text {ur (ref) }} \\
(\mathrm{MPa})\end{array}$ & $\begin{array}{c}c \\
(\mathrm{kPa})\end{array}$ & $\begin{array}{c}\phi \\
\left({ }^{\circ}\right)\end{array}$ & $v_{u r}$ & $\begin{array}{c}p_{(\text {ref })} \\
(\mathrm{kPa})\end{array}$ & $m$ & $K_{0}$ \\
\hline Reactive Clay & 18 & 2 & 2 & 6 & 2 & 24 & 0.2 & 50 & 0.5 & 0.5 \\
\hline Dense Sand (drained) & 20 & 75 & 75 & 200 & 0.1 & 36 & 0.2 & 100 & 0.5 & 0.4 \\
\hline Granular Pile (drained) & 22 & 200 & 200 & 600 & 0.1 & 40 & 0.2 & 100 & 0.5 & 0.4 \\
\hline
\end{tabular}

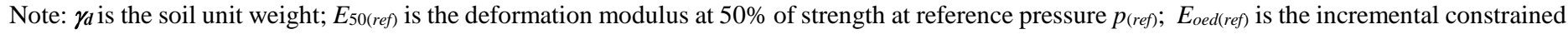
modulus at reference pressure; $E_{u r(r e f)}$ is the unload-reload deformation modulus at reference pressure; $c$ is the soil cohesion; $\phi$ is the soil peak friction angle; $v_{u r}$ is the unload-reload Poisson's ratio; $m$ defines dependency of stiffness on lateral effective stress; $K_{o}$ is the coefficient of earth pressure at rest.

The Efficiency of the GPAF system in arresting the deformation of foundations is clearly illustrated in Figure 11, which shows the heave response of the single footing versus the free field heave. As expected, it can be seen that the footing movement is strongly dependent on the pile diameter; the ability of the system to resist various rates of heave seems to improve with increasing the pile diameter. As expected, the load displacement response (Figure 12) of the pile anchor for different diameters of the granular pile indicates that both pile resistance and stiffness increase with increasing pile diameter. However, while the stiffness increases steadily with the pile diameter, the pile size effect on resistance is more dramatic when the pile diameter increases from $0.25 \mathrm{~m}$ to $0.5 \mathrm{~m}$ than from $0.5 \mathrm{~m}$ to $1.0 \mathrm{~m}$. Examination of the FEM results showed that this cannot be attributed to the resistance component induced by the pile weight; it is rather associated with the failure mechanism which extends outside the pile periphery and engages more soil zones as the diameter increased from $0.25 \mathrm{~m}$ to $0.5 \mathrm{~m}$.

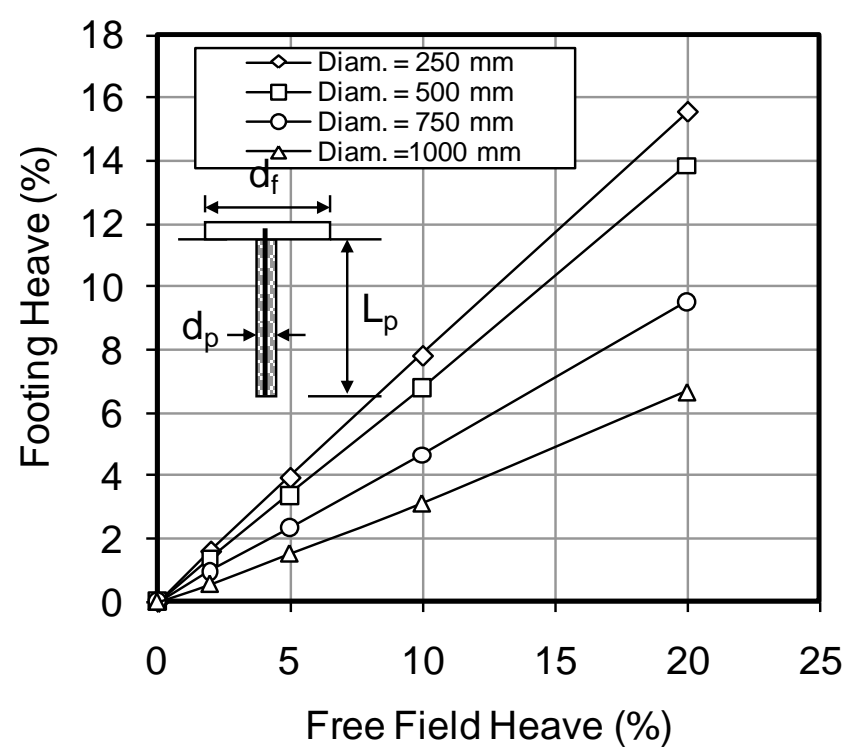

Fig. 11: Heave response of the GPAF system [20].

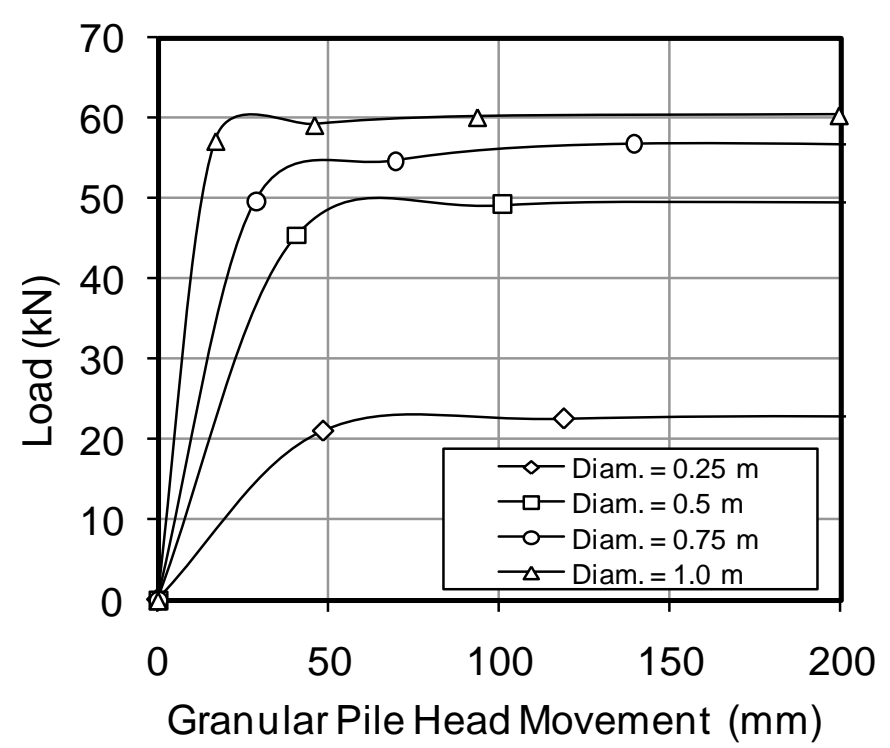

Fig. 12: Load settlement curve of the GPAF system [20].

Figure 12 indicates that establishing the pile resistance response curve is critical in designing the GPAF system for determination of the allowable uplift force that can be resisted by the system and associated allowable heave. For example, it can be inferred that the significant increase in the pile stiffness with increasing the pile diameter could have an adverse effect on the efficiency of the system. The relatively low displacements required to mobilize the full strength of the granular 
pile system commensurate with the behavior of the conventional, frictional piles that derive their resistance from only skin friction or adhesion. The efficiency of the GPAF system can be expressed in terms of the ratio of the heave experienced by the footing $\left(\Delta H_{\text {footing }}\right)$ to that of the free field $\left(\Delta H_{\text {free }}\right)$, as follows:

$$
\text { Effeciency }(\%)=\frac{\Delta H_{\text {footing }}}{\Delta H_{\text {free }}} \times 100
$$

For a given length of the granular pile, the efficiency depends on ratio of the relative width of the granular pile to the footing width $\left(d_{p} / d_{f}\right)$, where $d_{p}$ is the pile diameter and $d_{f}$ is the footing diameter. The influence of the ratio $d_{p} / d_{f}$ is presented in Figure 13 for various heave percentages. It can be observed that the efficiency of the GPAF system increases significantly with the increase in ratio $d_{p} / d_{f}$, and it can also be observed that the efficiency of the GPAF system is relatively insensitive to the heave magnitude. It follows from the above discussion that the suitability of the GPAF system depends primarily on the efficiency required to be achieved by the system and the response of the pile load-displacement.

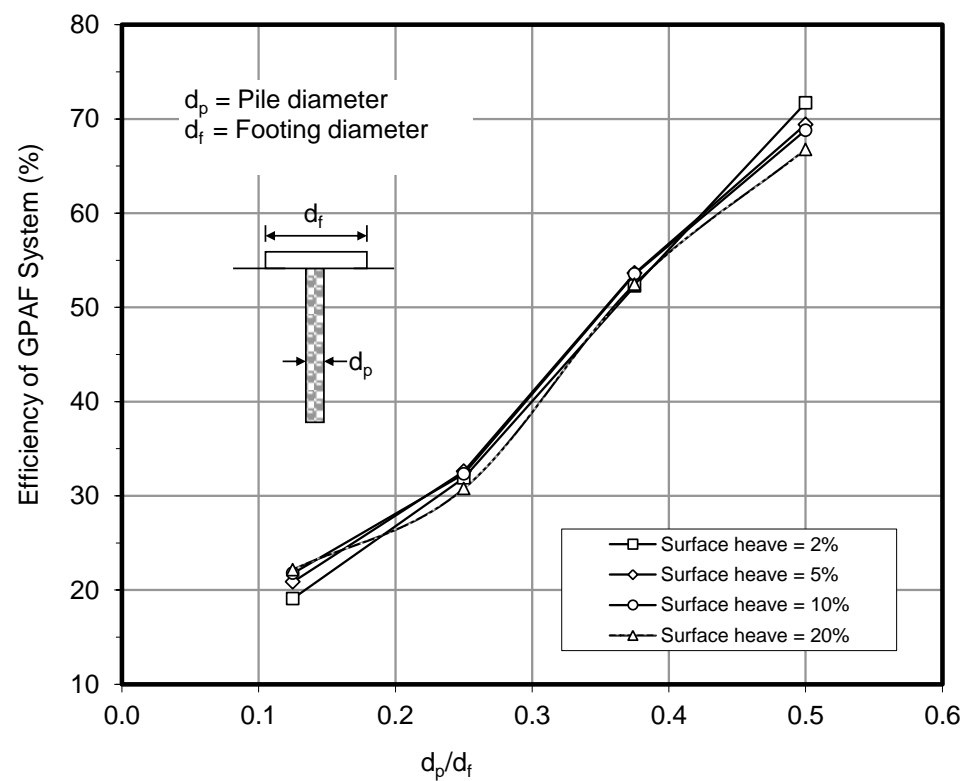

Fig. 13: Influence of footing ratio $\left(d_{p} / d_{f}\right)$ on the efficiency of the GPAF system [20].

The suitability of the GPAF system to resist the shrinkage events when reactive soil loses moisture was also addressed. Under such events the granular pile will be subjected to compressive force, which may lead to bulging into the surrounding reactive soil and resulting in either failure of the foundation system or excessive settlement. This may also be associated with possible buckling of the pile anchor, which will be subjected to a compressive force if rigidly connected to the foundation element. In order to enable the GPAF system to resist shrinkage, the granular pile is encased in a geogrid to reinforce the pile by providing hoop resistance during the shrinkage events. The effect of geogrid on resistance shrinkage of the reactive clay was explored by modeling the geotextile element in PLAXIS and different axial stiffness values were investigated. Both the efficiency of the geogrid and influence of its axial stiffness on arresting shrinkage under the modeled footing are evident from the settlement curve in Figure 14, for 5\% shrinkage. For example, the case of $E A_{(\text {Geofabric })}=2000 \mathrm{kN} / \mathrm{m}$ reduced the settlement by about 55\% compared to the case of no geogrid. Similarly, the successful role of the geogrid in reducing the bulging of the granular pile is demonstrated in Figure 15, which shows variation of the lateral movement along the horizontal line passing through the mid-height of the granular pile. 


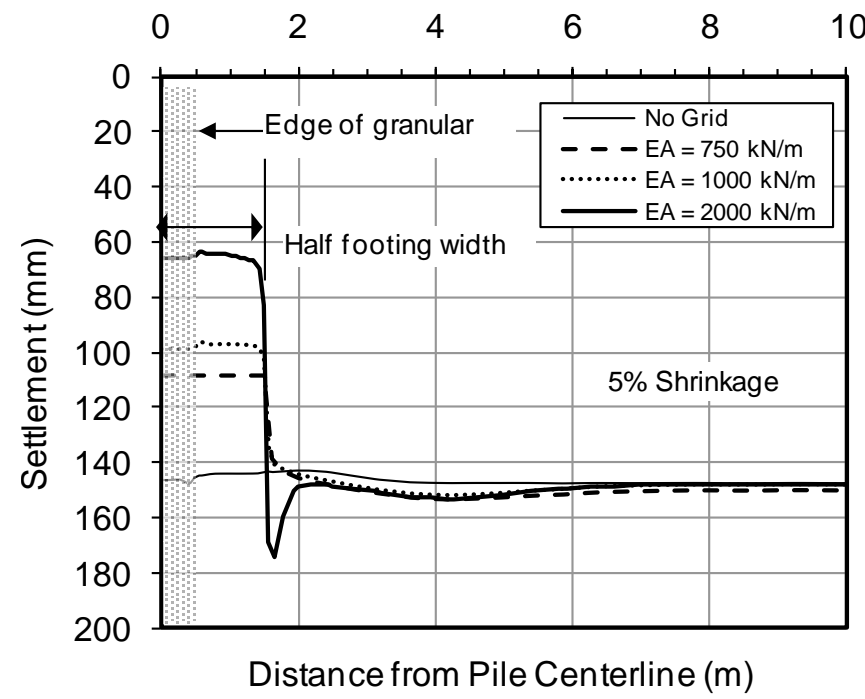

Fig. 14: Settlement trough during a shrinkage event [20].

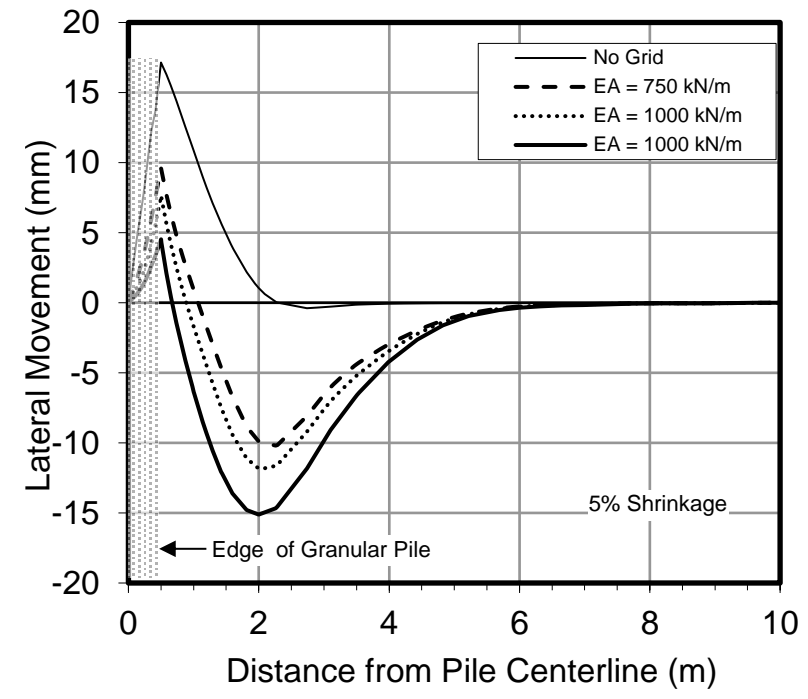

Fig. 15: Effect of geogrid in reducing bulging of the granular pile [20].

\subsection{Numerical Modelling Analysis of Two-Storey Building on GPAF System}

In order to investigate the efficiency of the GPAF system in practice, a two-story four-bay frame building resting on pad footing with the GPAF system was modelling and analyzed using PLAXIS 3D [23]. An additional independent analysis was also carried out for the same building resting on pad footings without the GPAF and the results were compared with those obtained from the analysis of the building resting on the GPAF system. The two-story building considered was $6 \mathrm{~m}$ high (each story is $3 \mathrm{~m}$ in height), and $20 \mathrm{~m} \times 20 \mathrm{~m}$ in plan with each bay having dimensions of $5 \mathrm{~m} \times 5 \mathrm{~m}$. A ceiling slab of $160 \mathrm{~mm}$ thick was assumed for each story. The slabs are supported by beams, $300 \mathrm{~mm}$ wide and $400 \mathrm{~mm}$ deep, which in turn rest on square columns of dimensions $300 \mathrm{~mm} \times 300 \mathrm{~mm}$. The dead load of each structural component of the frame building was considered according to the material unit weight of that component and an additional distributed live load of $5 \mathrm{kPa}$ was also assumed to act on top of the slabs. All building materials (including footings) were made of concrete of an elastic modulus of $35 \mathrm{GPa}$, Poisson's ratio of 0.2 and unit weight of $24 \mathrm{kN} / \mathrm{m}^{3}$. The GPAF system consisted of square pad footings of dimensions $2 \mathrm{~m} \times 2 \mathrm{~m}$, each supported on a granular pile of $0.5 \mathrm{~m}$ in diameter and $3.0 \mathrm{~m}$ in length. The problem is presented in Figure 16, which shows the 3D FEM model of the problem with a discretized mesh that consists of 17,880 wedge elements of 15 displacement nodes.

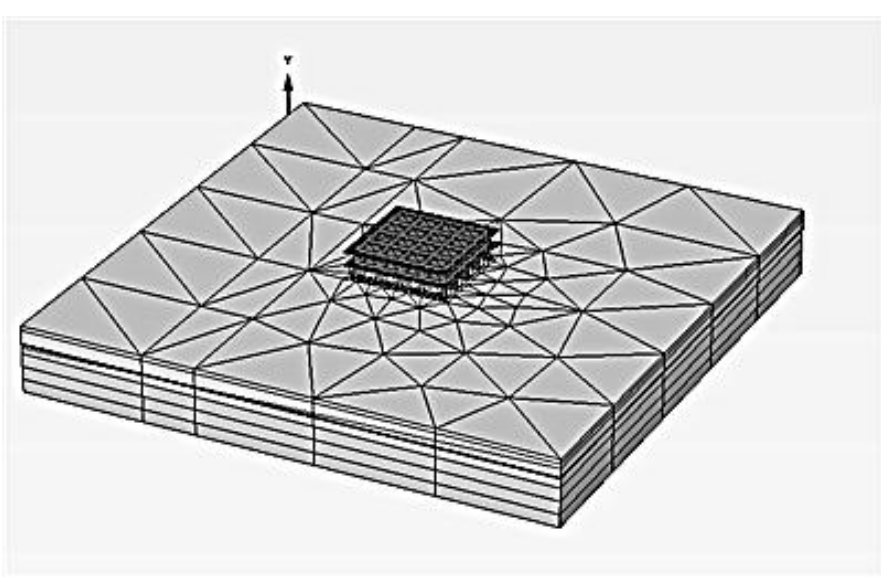

(a)

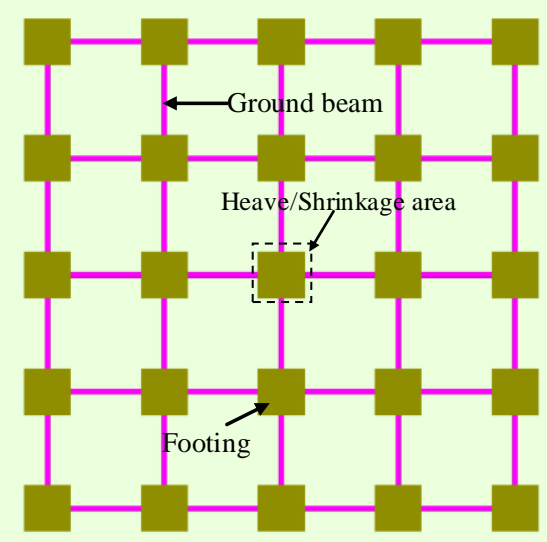

(b)

Fig. 16: FEM 3D model: (a) mesh discretisation of a double-storey frame building constructed on GPAF system; and (b) plan view of building foundation [24]. 
A comparison was made for the top beams (denoted as B1-B4) of the central frame in terms of induced deformations due to heave and shrinkage, as shown in Figure 17, and the angular distortions and bending moments due to heave are given in Table 2. It can be seen from Figure 17 that the ability of the pad footings to resist the vertical movements induced by the soil heave is significantly improved when the GPAF system is used. The maximum vertical displacement induced by the soil heave for the beams considered without the GPAF system was found to be equal to $6.7 \mathrm{~mm}$, whereas negligible vertical movement was developed when the GPFA system is used. More importantly, it can be seen from Table 2 that all beams considered undergo much less angular distortions when the GPFA system is used. For example, the angular distortion of beam B2 without the GPAF system is 300 times greater than that experienced when the GPAF system is used.

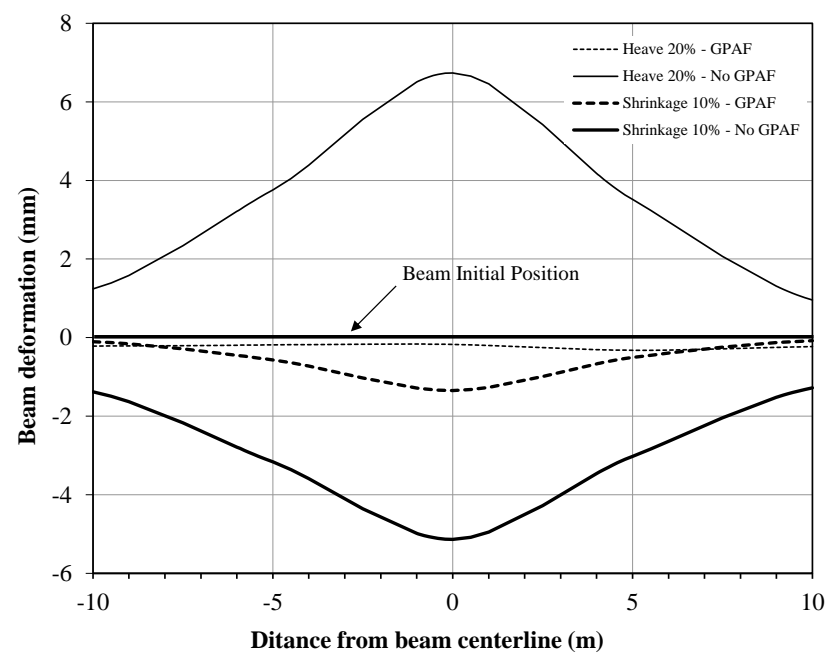

Fig. 17: Deformation of central beams B1 to B4 due to heave and shrinkage [24].

Table 2: Angular distortions and internal forces of building central beams due to heave [24].

\begin{tabular}{|c|l|c|c|c|}
\hline \multicolumn{2}{|c|}{$\begin{array}{c}\text { Beam } \\
\text { Number }\end{array}$} & $\begin{array}{c}\text { Angular distortion } \\
\left(\times 10^{-5}\right)\end{array}$ & $\begin{array}{c}\text { Maximum negative moment } \\
(\mathrm{kN.m})\end{array}$ & $\begin{array}{c}\text { Maximum positive } \\
(\mathrm{kN} . \mathrm{m})\end{array}$ \\
\hline \multirow{2}{*}{ B1 } & GPAF & 0.6 & 44.6 & 23.0 \\
\cline { 2 - 5 } & No GPAF & 50 & 81.2 & 29.3 \\
\hline \multirow{2}{*}{ B2 } & GPAF & 0.2 & 59.8 & 26.0 \\
\cline { 2 - 5 } & No GPAF & 59 & 130.2 & 25.3 \\
\hline \multirow{2}{*}{ B3 } & GPAF & 2.8 & 58.0 & 28.0 \\
\cline { 2 - 5 } & No GPAF & 64 & 132.4 & 25.0 \\
\hline \multirow{2}{*}{ B4 } & GPAF & 1.8 & 44.0 & 29.6 \\
\cline { 2 - 5 } & No GPAF & 51 & 79.7 & \\
\hline
\end{tabular}

Note: $20 \%$ Heave: Free field heave $=75 \mathrm{~mm}$

In terms of the suitability of the GPAF system to resist shrinkage when the reactive soil loses moisture, it can be readily shown from Figure 17 that under such an event the GPAF system is capable of arresting the shrinkage and reducing its induced settlement. It was found that the maximum beam settlement induced by soil shrinkage for the building with the GPAF system was reduced by $75 \%$ compared to the case of no GPAF system. It should be noted that the capacity of the GPAF system to resist shrinkage is a result of its ability to bear directly on the piles (while still in contact with the shrinking soil), which in turn could engage the bearing capacity of the sand layer that embrace the base plate. Given that the granular pile has no tension or bending capacity, it is therefore expected that the maximum capacity to resist shrinkage will be reached when the shrinking soil detaches itself completely from the granular pile. In such a case the shrinkage resistance can be significantly improved by encasing the granular pile into a stiff, geogrid case to stop the pile from bulging. As can be seen in Table 2, the use of the GPAF system significantly reduced the maximum negative bending moments of all beams, but 
slightly reduced the maximum positive bending moments. For example, the maximum negative and positive moments of beam B1 are 81.2 and $29.3 \mathrm{kN}$.m, respectively, for the case without the GPAF system, whereas these values are reduced to 44.6 and $23.0 \mathrm{kN} . \mathrm{m}$, respectively, for the case with the GPAF system. The practical implication of these results is that the use of the GPAF system for light-weight structures can significantly reduce the superstructure damage induced by reactive soils, leading to cost savings of structural repairs and ongoing maintenance.

\section{Prefabricated Vertical Drains for Soft Clay}

The use of prefabricated vertical drains (PVDs) in combination with pre-loading has become a popular technique to enhance the bearing capacity of soft soils by accelerating soil consolidation. The degree of consolidation achieved by PVDs is greatly controlled by some soil properties (e.g. soil permeability and volume compressibility) that are highly variable from one point to another in the ground and potentially induce uncertainty in their characterization. The inherent variation of soil properties with respect to spatial location is known as soil spatial variability which is due to the uneven soil micro fabric, complex characteristics of geological deposition and stress history. The geotechnical community is well aware of the fact that soils are inherently variable in the ground and in recent years there has been an increasing interest worldwide to consider the soil spatial variability in design of many geotechnical engineering applications. However, owing to the complexity of the problem of soil consolidation by PVDs, soil spatial variability has rarely been taken into consideration in most available design methods of ground improvement by PVDs. Current design methods of ground improvement by PVDs are typically carried out by assuming a single best estimate of the degree of consolidation based on "average" soil properties that are used to define an "equivalent" homogeneous soil. In reality, however, soil is rarely homogeneous and an assumption of soil homogeneity usually results in unsatisfactory agreement between the desired (predicted) and actual (observed) consolidation values, leading to unreliable and uneconomical design. In this paper, a rigorous stochastic modelling approach carried out by the author and his co-workers is presented, which allows the nature of soil spatial variability to be implemented in design using statistical methods. The basic notion of this approach involves the development of advanced 3D models that merge the random field theory and finite element method into a Monte-Carlo frame work, and many parameters affecting the behaviour of soil consolidation were investigated and previously presented in many publications [see 25, 26-29]. The studies were carried out for unit cell (single drain) and multi-drain analyses and the results highlighted the significant role of soil spatial variability in ground improvement by PVDs, and elucidated the importance of proper modelling of the soil spatial variability role in design. In this section, the main concept of the proposed stochastic solutions is described and some obtained results for the unit cell analysis are presented and discussed.

\subsection{Stochastic Modelling for Design of Soil Consolidation by PVDs}

In order to consider soil spatial variability in the course of design of ground improvement by PVDs, true site conditions of soil properties that vary in a random fashion within the soil mass need to be modeled in the design process. This is achieved in this work by creating virtual or simulated soil profiles that are merged with a finite element modeling of soil consolidation by PVDs in a Monte Carlo framework. For a certain problem of ground improvement by PVDs, the proposed approach can be applied using the following steps:

1. Create a virtual soil profile for the problem in hand which comprises a grid of elements that are assigned design values of soil properties different from one element to another across the grid. The virtual soil profile allows arbitrary distributions of the soil properties to be realistically modeled;

2. Incorporate the generated soil profile into a finite element modeling of soil consolidation by PVDs; and

3. Repeat Steps 1 and 2 many times using the Monte Carlo technique so that a series of consolidation responses can be obtained from which the probability of achieving a target degree of consolidation can be estimated and analyzed.

The above steps are applied to a unit cell consolidation problem of geometry (see Figure 18a): $L=1.0 \mathrm{~m}, R_{e}=0.85$ $\mathrm{m}, r_{w}=0.05 \mathrm{~m}$, where $L$ is the maximum vertical drainage distance; $R_{e}$ is the radius of equivalent soil cylinder with impermeable perimeter or the radius of zone of influence; and $r_{w}$ is the equivalent radius of the drain. Details of the steps used, as well as the numerical procedures, are described below.

\section{Creation of Virtual Soil Profiles}


Prior to proceeding with this step, it is necessary to identify the soil properties that have the most significant impact on soil consolidation by PVDs so that they can be treated as random variables when creating the virtual soil profiles. Among all soil properties, soil permeability and volume compressibility have the most significant impact on soil consolidation by PVDs, as indicated by several researchers [e.g. 30, 31]. However, in the study presented herein, only soil permeability was treated as a random variable and other soil properties were assumed to be constant. It should be noted that soil permeability can possess a spatial variability of as high as $300 \%$ [32]. Consequently, the assumption that soil permeability provides the most significant impact on soil consolidation is viable. Fortunately, whilst spatial variability of soil properties vary randomly in the ground, such variation is gradual and follows a pattern that can be quantified using spatial correlation structures [33]. In this paper, spatially correlated soil properties and profiles were simulated using the random field theory [34] and local average subdivision (LAS) process [33].

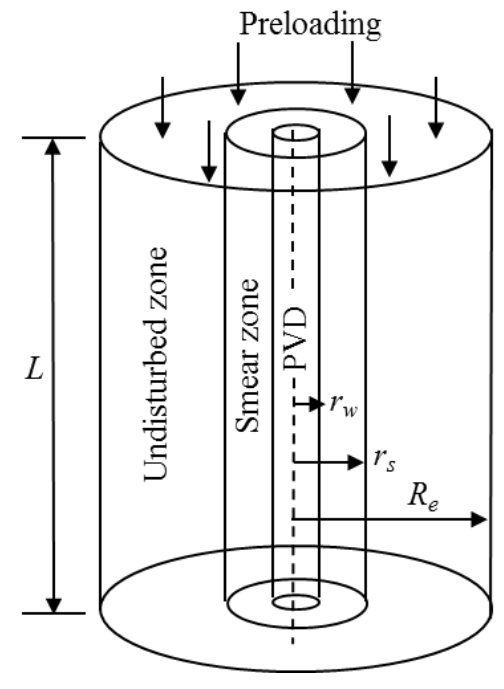

(a)

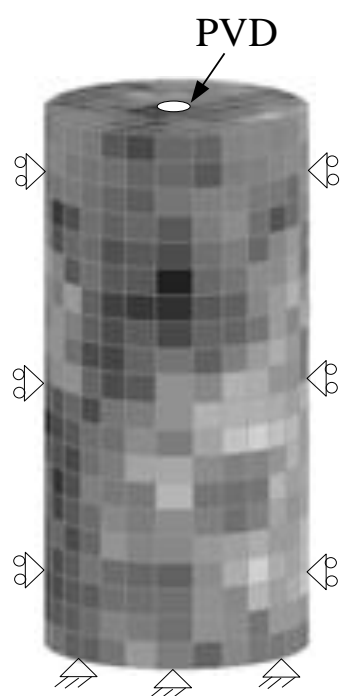

(b)

Fig. 18: Stochastic modelling of soil consolidation by PVDs: (a) cylindrical unit cell; and (b) FEM mesh discretization.

To create a virtual soil profile, a random field was generated in the form of a grid of cells that were assigned values of soil permeability different from one another across the grid. The generated random field was then mapped onto a finite element modelling of soil consolidation by PVDs, taking into account the number and size of the FE mesh elements. The value of soil permeability assigned to each element of the grid is itself a random variable, thus the FE mesh contains a number of random variables that is equal to the number of the FE mesh elements. To simulate the above process, the following spatial variability characteristics of soil permeability need to be identified: the mean $(\mu)$, standard deviation $(\sigma)$, probability distribution and correlation length $(\theta)$. In order to determine these characteristics for a certain site, a geotechnical investigation program of closely-spaced soil testing in the vertical and horizontal directions needs to be undertaken and obtained field data analyzed. However, such a comprehensive site investigation is often beyond the scope of most projects. Consequently, in the absence of such site information, traditional site investigation together with information from geological maps and knowledge from previous site investigations of nearby locations can be used to assign a particular level of spatial variability to the site in question. In addition, there are increasing number of available publications that can be used to provide typical ranges of statistical parameters of most soil properties [e.g. 35, 36, 37].

In the current study, the distribution of the random field of soil permeability, $k$, was defined by a probability density function in which the variability of $k$ was assumed to follow a lognormal distribution defined by the mean, $\mu_{k}$, and standard deviation, $\sigma_{k}$. The selection of lognormal distribution for $k$ was based on findings from field tests data of soil permeability reported by Hoeksema and Kitanidis [38] and Sudicky [39]. In addition, there is also a number of previous studies in which soil permeability was characterized by lognormal distribution [e.g. 40, 41, 42]. In the process of simulating the lognormally distributed random field of $k$, correlated local averages of standard normal random field $G(x)$ were generated with zero mean, unit variance and spatial correlation function using the LAS process [33]. The correlation coefficient between $k$ measured at 
a point $x_{1}$ and a second point $x_{2}$ was specified by a correlation function, $\rho(\tau)$, where $\tau=\left|x_{1}-x_{2}\right|$ is the absolute distance between the two points. An exponentially decaying (Markovian) spatial correlation function was used, as follows [43]:

$$
\rho(\tau)=\exp \left(-\sqrt{\left(\frac{2\left|\tau_{h}\right|}{\theta_{h}}\right)^{2}+\left(\frac{2\left|\tau_{v}\right|}{\theta_{v}}\right)^{2}}\right)
$$

where: $\left|\tau_{h}\right|$ and $\left|\tau_{v}\right|$ are the absolute distances between two points in the horizontal and vertical directions, respectively; $\theta_{h}$ and $\theta_{v}$ are the spatial correlation lengths in the horizontal and vertical directions, respectively. For an isotropic condition, $\theta_{h}=\theta_{v}=\theta$ and Equation (1) reduces to:

$$
\rho(\tau)=\exp \left(-\frac{2|\tau|}{\theta}\right)
$$

The correlation length (also known as scale of fluctuation) controls the decay rate of the correlation function given in Equations (3) and (4), i.e. it describes the limit of spatial continuity of spatial correlation. In other words, the random variables of the soil permeability field generated above can be correlated to one another by controlling the spatial correlation length, $\theta$. For example, a large value of $\theta$ indicates a smoothly varying field, whereas a small value of $\theta$ implies an erratic field. It is noteworthy that $\theta$ is estimated with respect to the underlying normally distributed random field (ln $k$ ) and the correlation coefficient operates between the values of $\ln k$. In this study, only isotropic correlation structure (i.e. $\theta_{h}=\theta_{v}=\theta$ ) of soil permeability is considered for simplicity. Because $k$ was assumed to be characterized statistically by a lognormal distribution, the correlated standard normal random field, $G(x)$, generated by LAS method was then transformed into a lognormal distribution using the following transformation function [43]:

$$
k_{i}=\exp \left\{\mu_{\ln k}+\sigma_{\ln k} G\left(x_{i}\right)\right\}
$$

where: $x_{i}$ and $k_{i}$ are, respectively, the vector containing the coordinates of the center of the $i$ th element and the soil property value assigned to that element; $\mu_{\ln k}$ and $\sigma_{\ln k}$ are the mean and standard deviation of the underlying normal distribution; $\mu_{\ln k}$ and $\sigma_{\ln k}$ are obtained from the specified permeability $\mu_{k}$ and $\sigma_{k}$ using the following lognormal distribution transformation functions (Fenton and Griffiths 2008):

$$
\begin{gathered}
\mu_{\ln k}=\ln \mu_{k}-\frac{1}{2} \sigma_{\ln k}^{2} \\
\sigma_{\ln k}=\sqrt{\ln \left(1+\frac{\sigma_{k}^{2}}{\mu_{k}^{2}}\right)}=\sqrt{\ln \left(1+v^{2}\right)}
\end{gathered}
$$

where: $v=\sigma_{k} / \mu_{k}$ is the coefficient of variation of permeability.

\section{Finite Element Modeling Incorporating Soil Spatial Variability}

With the complete subsurface profile having been simulated in the previous step, the spatial variability of soil permeability is now known and can be employed as input in a finite element consolidation modelling of soil improvement by PVDs. All numerical analyses were carried out using the finite element computer program AFENA [44] in which the soil consolidation was treated as a coupled transient problem governed by the Biot's consolidation theory [45] and the analyses were performed for both the smear and no smear cases. When the smear effect was taken into consideration, two independent random fields of soil permeability were generated separately (one for the smear zone and another for the undisturbed zone) using the specified statistical parameters of each zone. Both random fields were then mapped onto the corresponding grid in 
the finite element mesh. It should be noted that, for simplicity, the well resistance factor which may affect the rate of consolidation was not considered in the presented work.

In soil improvement by PVDs, soil consolidation takes place by combined vertical and horizontal (radial) water drainage. However, the drainage length in the vertical direction is significantly larger than that of the horizontal direction and permeability in the horizontal direction is often much higher than that of the vertical direction [46]. Consequently, soil consolidation due to vertical drainage is much less than that of the horizontal drainage. Under this reasoning, only soil consolidation due to horizontal drainage was analyzed in the current study. In the sections that follow and since only soil consolidation due to horizontal drainage was considered, the degree of consolidation due to the horizontal drainage, $U_{h}$, and permeability in the horizontal direction, $k_{h}$, were simply denoted as $U$ and $k$, respectively. The soil skeleton was modeled as a linear elastic solid with spatially variable coefficient of permeability, $k$, constant modulus of elasticity $E^{\prime}=5 \mathrm{MPa}$ and Poisson's ratio $v^{\prime}=0.25$. A single generation of a random field and subsequent finite-element analysis of that field are termed "realization". For an individual realization, the degree of consolidation, $U$, at any certain consolidation time, $t$, was calculated in terms of excess pore water pressure with the help of the following expression:

$$
U=1-\frac{\bar{u}}{u_{0}}
$$

where: $\bar{u}$ and $u_{0}$ are the initial uniform and average excess pore water pressures, respectively. It has to be emphasized that the average excess pore pressure $(\bar{u})$ was obtained by performing numerical integration over the depth and width of the discretized mesh.

The effect of spatially variable of $k$ on the behavior of soil consolidation by PVDs was investigated over a range of different combinations of standard deviation, $\sigma_{k}$, and scale of fluctuation, $\theta$, while the mean value of the coefficient of permeability was kept at a fixed value equal to $\mu_{k}=5 \times 10^{-10} \mathrm{~m} / \mathrm{sec}$. However, when the smear effect was considered, the mean values of the coefficient of permeability in the undisturbed and smear zones were taken to be equal to $\mu_{k_{u}}=5 \times 10^{-10}$ and $\mu_{k_{s}}$ $=2.5 \times 10^{-10} \mathrm{~m} / \mathrm{sec}$, respectively, which means that $\mu_{k_{u}} / \mu_{k_{s}}=2.0$. It should be noted that $\sigma_{k}$ was presented in a normalized form as $v$ (i.e. coefficient of variation), and the considered values of $v$ and $\theta$ are as follows:

- $\quad v(\%)=25,50,100,200$ and 400

- $\theta=0.125,0.25,0.5,1.0,2.0$ and 4.0

It should be noted that since the spatial variation of soil permeability is known to be very large and possibly as high as $300 \%$ [36, 37], the upper limit of $v$ was set to be equal to $400 \%$. Conceptually, soil can have a scale of fluctuation from zero to infinity. However, in practice, the scale of fluctuation tends to be related to the size of the domain over which its estimate is taken and is typically significantly smaller than the sampling domain $[47,48]$. For this reason, it was believed that the values of spatial variability parameters used above represent a sufficiently practical range to establish general trends for the stochastic soil consolidation behavior. As mentioned earlier, in order to take the smear effect into account, two independent random fields of soil permeability were generated for the undisturbed and smear zones. In such case, $v$ and $\theta$ were denoted as $v_{u}$ and $\theta_{u}$, respectively, for the undisturbed zone, whereas they were denoted as $v_{s}$ and $\theta_{s}$, respectively, for the smear zone.

\section{Repetition of Process using the Monte Carlo Technique}

Following the Monte Carlo technique, the process of generating a random permeability field and subsequent finite element analysis were repeated 1000 times to give reasonably stable statistics for the output quantities of interest. At each realization of the Monte Carlo process, the random soil permeability field was generated using the same $v$ and $\theta$, but with spatial distribution of soil permeability varied from one realization to the next. The nature of the generated random soil property fields (whether uniform or erratic) was regulated by the magnitudes of $v$ and $\theta$. Figure 18(b) shows a typical example of a discretized mesh and the corresponding soil domain represented by a grey scale of a typical permeability field in which the magnitude of soil permeability remains constant within each FE elements but different from one element to another. The lighter elements represent "higher" soil permeability regions, whereas the darker elements refer to "lower" soil permeability 
regions. Each realization of the Monte Carlo process differs in the locations at which low and high permeability zones are situated. For example, in one realization, more low permeability regions may be situated in locations near to the PVD causing lower drainage rate, whereas in another, high permeability regions in those locations means faster drainage rate. For certain values of $v$ and $\theta$, the obtained outputs from the suite of 1000 realizations of the Monte Carlo process were collated and statistically analyzed to produce estimates of the probability density functions and probability events of achieving certain degrees of consolidation, as shown below in Figures 19 to 22. In these figures, a parametric study that investigates the effects of spatial variability of $k$ on soil stabilization by PVDs is presented, where $P\left[U \geq U_{90}\right]$ is expressed as a function of the consolidation time $t$. In order to put the stochastic analyses into context, an initial deterministic solution was also performed for the smear and non-smear cases by assuming a homogeneous soil and the deterministic solutions are shown in the presented figures by vertical solid lines.

\subsection{Effects of Spatial Variability of Soil Permeability in Case of no Smear}

The effects of spatial variability of $k$ on the stochastic behavior of soil consolidation by PVDs for the case of no smear are shown in Figures 19 and 20. In Figure 19, the influence of $v$ on $P\left[U \geq U_{90}\right]$ is illustrated for a fixed value of $\theta=1.0$. It can be seen that, for all curves, $P\left[U \geq U_{90}\right]$ increases with the increase in consolidation time, as expected. It can also be seen that, at any certain consolidation time, $P\left[U \geq U_{90}\right]$ decreases with the increase of $v$, implying that the probability of achieving $90 \%$ target degree of consolidation decreases with the increase of spatial variability of soil permeability. This is almost true for all consolidation times despite the slight discrepancy of results at lower probability of $P\left[U \geq U_{90}\right] \leq 0.2$.

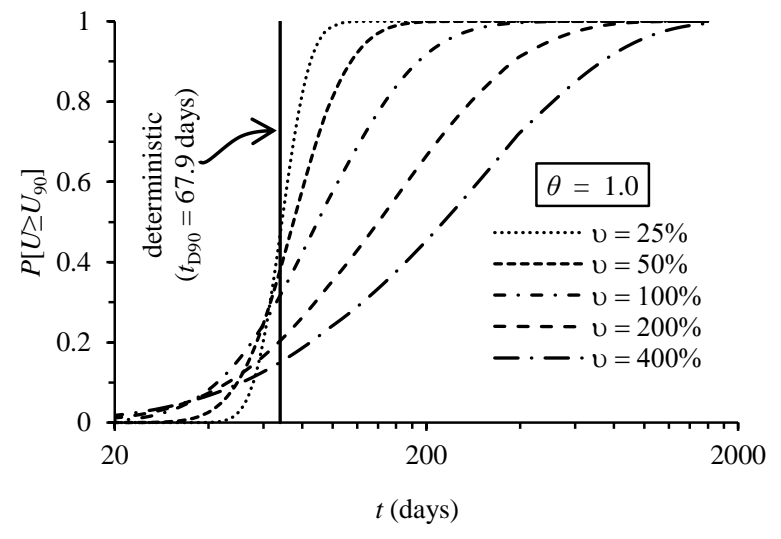

Fig. 19: Effect of $v$ at fixed value of $\theta=1.0$ [49].

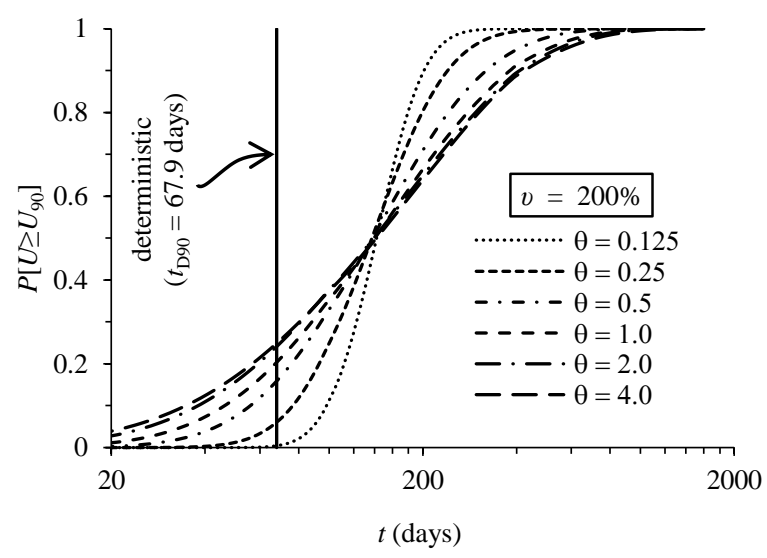

Fig. 20: Effect of $\theta$ at fixed value of $v=200 \%$ [49].

Figure 20 shows the effect of $\theta$ on $P\left[U \geq U_{90}\right]$ for a fixed value of $v=200 \%$. It can be seen that, as expected, $P[U \geq$ $\left.U_{90}\right]$ increases with the increase of $t$ for all $\theta$; however, all curves crossover at a critical value of $P\left[U \geq U_{90}\right] \approx 50 \%$ where $P\left[U \geq U_{90}\right]$ becomes independent of $\theta$. At any certain time prior to the crossover point, $P\left[U \geq U_{90}\right]$ increases with the increases of $\theta$, whereas after the crossover point, $P\left[U \geq U_{90}\right]$ decreases with the increases of $\theta$. It can also be seen that, for all curves, there is an increasing rate in $P\left[U \geq U_{90}\right]$ with respect to $t$ as $\theta$ decreases. The explanation behind this behavior lies in the fact that for vanishingly small $\theta$, the soil becomes infinitely rough (i.e. any point at which soil has low permeability, it will be surrounded by points where the soil has high permeability). What this means is that the flow path initially becomes increasingly tortuous with longer drainage length, hence, the flow is forced to find a shorter passage cutting through the low permeability regions. In contrast, for larger $\theta$, regions of low permeability are bunched together and as a result, the draining pore water detour the bunched up low permeability regions instead of cutting through them which leads to a longer drainage length and consequently slower increasing rate of $P\left[U \geq U_{90}\right]$ with respect to $t$. The closely grouped curves corresponding to $\theta=1.0,2.0$ and 4.0 clearly demonstrate that $P\left[U \geq U_{90}\right]$ becomes insensitive of $\theta \geq 1.0$. By comparing Figures 19 and 20 , it can be seen that $P\left[U \geq U_{90}\right]$ is relatively less sensitive to $\theta$ than $v$. The above analysis is repeated over a range of combination of $v$ and $\theta$ and similar trends were obtained. It should be noted that the deterministic solution of this case yielded $U_{90}$ at $t=$ 67.9 days (i.e. $t_{\mathrm{D} 90}=67.9$ days), and it is interesting to know that this deterministic solution yielded $P\left[U \geq U_{90}\right]<50 \%$ for all combinations of values of $v$ and $\theta$. This means that the deterministic predicted consolidation time will have at least $50 \%$ risk of not being able to achieve $90 \%$ consolidation. 


\subsection{Effects of Spatial Variability of Soil Permeability Considering Smear}

The effects of spatially variable of $k$ on the probability of achieving $90 \%$ consolidation for the case of considering smear are shown in Figures 21 and 22. In Figure 21, the effects of $v_{u}$ and $v_{s}$ on $P\left[U \geq U_{90}\right]$ at fixed values of $\theta_{u}=\theta_{s}=2.0$ are shown. In Figure 21(a), it can be seen that at any consolidation time, $P\left[U \geq U_{90}\right]$ decreases with the increases of $v_{u}\left(v_{s}\right.$ is fixed at 50\%); however, the effect of increasing $v_{u}$ on $P\left[U \geq U_{90}\right]$ remains marginal. The effect of $v_{s}$ at a fixed value of $v_{u}=$ $50 \%$ is shown in Figure 21(b), which shows that varying the values of $v_{s}$ has a considerable impact on the estimated values of $P\left[U \geq U_{90}\right]$. At any certain consolidation time, $P\left[U \geq U_{90}\right]$ decreases with the increases of $v_{s}$. The overall observation that can be derived from comparing the results in Figure 21 is that the decreasing rate of $P\left[U \geq U_{90}\right]$ is higher for the increasing value of $v_{s}$ than $v_{u}$, implying that the effect of $v_{s}$ on $P\left[U \geq U_{90}\right]$ is dominant.
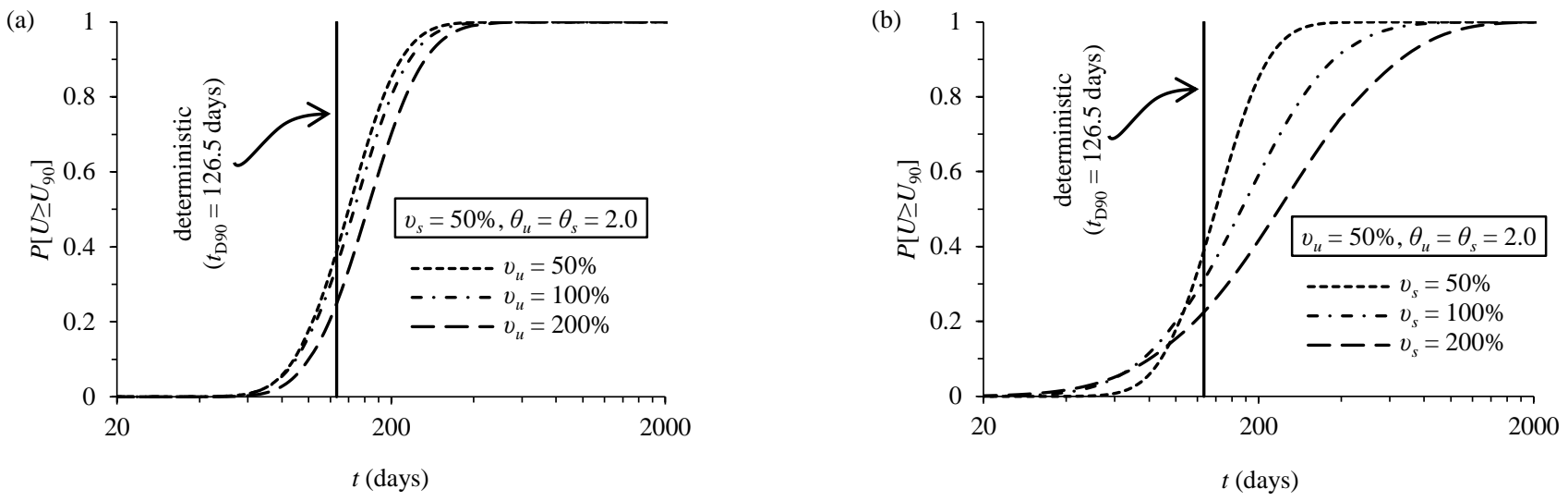

Fig. 21: Effect of $v_{u}$ and $v_{s}$ on $P\left[U \geq U_{90}\right]$ for $\theta_{u}=\theta_{s}=2.0$ [49].

Figure 22 illustrates the effects of $\theta$ on $P\left[U \geq U_{90}\right]$ at fixed values of $v_{u}=v_{s}=100 \%$. In Figure 22(a), the influence of $\theta_{u}$ on $P\left[U \geq U_{90}\right]$ is shown at $\theta_{s}=1.0$, and the results yield almost identical curves indicating that $\theta_{u}$ has no or very little impact on the probabilistic behavior of the degree of consolidation. On the other hand, the estimated $P\left[U \geq U_{90}\right]$ for different values of $\theta_{s}$ is plotted in Figure 22(b) at a fixed value of $\theta_{u}=1.0$. It can be seen that, unlike $\theta_{u}, \theta_{s}$ has a considerable impact on the estimated values of $P\left[U \geq U_{90}\right]$. Figure 22 reveals that, the effect of $\theta_{s}$ on $P\left[U \geq U_{90}\right]$ is more significant than $\theta_{u}$. It should be noted that the deterministic solution of this case yielded $U_{90}$ at $t=126.5$ days (i.e. $t_{\mathrm{D} 90}=126.5$ days), and again it is interesting to know that this deterministic solution yielded $P\left[U \geq U_{90}\right]<50 \%$ for all combinations of values of $v_{u}, v_{s}, \theta_{u}$, and $\theta_{s}$.
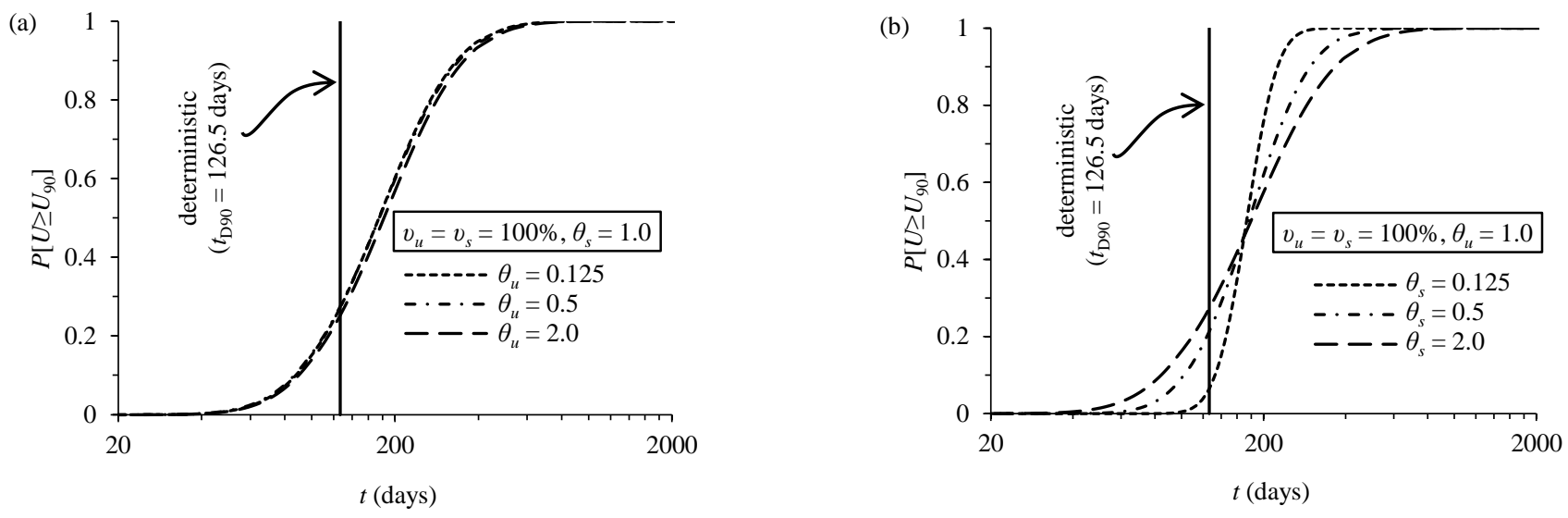

Fig. 22: Effect of $\theta_{u}$ and $\theta_{s}$ on $P\left[U \geq U_{90}\right]$ for $v_{u}=v_{s}=100 \%$ [49]. 


\section{Conclusions}

The results presented for bio-cementation by microbial-induced calcite precipitation (MICP) demonstrated that this promising ground improvement technique can significantly enhance the engineering properties of silica sand with high compressive strength. However, the efficiency of bio-cementation in improving the soil strength varied significantly according to the physical and environmental treatment conditions. The compacted sand of high initial density was found to achieve greater compressive strength than the un-compacted sand of lower initial density. It was also indicated that biocementation is able to process in different environmental conditions, such as extreme $\mathrm{pH}$ and high temperature. However, the compressive strength of treated soils was found to vary significantly depending on the treatment environmental conditions, with lower strength gained at hot temperature of $50^{\circ} \mathrm{C}$ and different values of $\mathrm{pH}$ than the neutral (i.e. $\left.\mathrm{pH}=7\right)$. It was also shown that it is possible to use the seawater as a chemical reagent for bio-cementation to replace the calcium chloride, and a significant strength improvement can be achieved after repeated treatments. This finding is interesting as it extends the application of bio-cementation to broader areas, such as ground improvement in marine environments. Marine bio-cementation can potentially contribute to more sustainable human activities and significantly benefit society in areas of offshore and onshore infrastructure protection and maintenance, as well as coastline erosion prevention.

The analyses presented for the granular pile anchor foundation (GPAF) system confirmed the potential use of this new technique in resisting the reactive soils for both the heave and shrinkage events. However, the success of the technique in real applications requires reasonable prediction of the load-displacement curve of the pile anchor. The results also showed that one critical limitation of the system may result from the fact that mobilization of the full skin resistance of the pile soil interface requires only small deformation. Further studies are required to explore this limitation whilst considering the working loads applied to foundations. The results also demonstrated the benefit of the GPAF system in reducing the vertical displacement and angular distortion of a light-weight structure induced by soil heave are quite significant, and it was observed that the resistance to shrinkage was improved immensely.

The results of soft clay consolidation by prefabricated vertical drains (PVDs) clearly demonstrated the potential of using the proposed probabilistic context in providing valuable insights into the impact of soil spatial (inherent) variability on ground improvement by PVDs. It was shown that spatial variability of soil permeability of an affected soil mass significantly influences the degree of consolidation achieved via PVDs and hence, the amount of obtained soil consolidation. The results confirmed the urge of using probabilistic techniques in routine design practice for ground improvement by PVDs.

\section{Acknowledgements}

The author gratefully acknowledges the contributions made by several co-workers and colleagues, including Dr Mostafa Ismail, Dr Md. Wasiul Bari and Dr Liang Cheng. The author also thanks his former PhD and undergraduate students who contributed to the experimental programme of presented work.

\section{References}

[1] J. T. DeJong, B. M. Mortensen, B. C. Martinez, and D. C. Nelson, "Bio-mediated soil improvement," Ecological Engineering, vol. 36, pp. 197-210, 2010.

[2] A. G. Phear and S. J. Harris, "Contributions to Geotechnique 1948-2008: Ground improvement," Geotechnique, vol. 58, pp. 399-404, 2008.

[3] J. Li, P. Tharakan, D. Macdonald, and X. Liang, "Technological, economic and financial prospects of carbon dioxide capture in the cement industry," Energy Policy, vol. 61, pp. 1377-1387, 2013.

[4] R. H. Karol, Chemical grouting and soil stabilisation. New York: Marcel Dekker, 2003.

[5] S. Stocks-Fischer, J. K. Galinat, and S. S. Bang, "Microbial precipitation of CaCO3," Soil Biology and Biochemistry, vol. 31, pp. 1563-1571, 1999.

[6] J. T. DeJong, M. B. Fritzges, and K. Nusslein, "Microbially induced cementation to control sand response to undrained shear," Journal of Geotechnical and Geoenvironmental Engineering, vol. 132, pp. 1381-1392, 2006.

[7] A. Al Qabany, K. Soga, and C. Santamarina, "Factors Affecting Efficiency of Microbially Induced Calcite Precipitation," Journal of Geotechnical and Geoenvironmental Engineering, vol. 138, pp. 992-1001, 2012.

[8] J. K. Mitchell and J. C. Santamarina, "Biological considerations in geotechnical engineering," Journal of Geotechnical and Geoenvironmental Engineering, vol. 131, pp. 1222-1233, 2005. 
[9] L. Cheng, M. A. Shahin, R. Cord-Ruwisch, M. Addis, T. Hartanto, and C. Elms, "Soil Stabilisation by MicrobialInduced Calcite Precipitation (MICP): Investigation into Some Physical and Environmental Aspects," in 7th International Congress on Environmental Geotechnics, Melbourne, Australia, 2014, pp. 1105-1112.

[10] M. P. Harkes, L. A. van Paassen, J. L. Booster, V. S. Whiffin, and M. C. van Loosdrecht, "Fixation and distribution of bacterial activity in sand to introduce carbonate precipitation for ground reinforcement," Ecological Engineering, vol. 36, pp. 112-117, 2010.

[11] L. Cheng, R. Cord-Ruwisch, and M. A. Shahin, "Cementation of sand soil by microbially induced calcite precipitation at various degrees of saturation," Canadian Geotechnical Journal, vol. 50, pp. 81-90, 2013.

[12] A. Dekuyer, L. Cheng, M. A. Shahin, and R. Cord-Ruwisch, "Calcium carbonate induced precipitation for soil improvement by urea hydrolysing bacteria," in World Congress on Advances in Civil, Environmental and Materials Research, Seoul, South Korea, 2012, pp. 2785-2793.

[13] L. Cheng, M. A. Shahin, and R. Cord-Ruwisch, "Bio-cementation of sandy soil using microbial-induced carbonate precipitation (MICP) for marine environments," Geotechnique, vol. 64, pp. 1010-1013, 2014.

[14] L. Cheng and M. A. Shahin, "Assessment of different treatment methods of microbial-induced calcite precipitation for clayey soil improvement," in 68th Canadian Geotechnical Conference, GeoQuebec 2015, Quebec, Canada, 2015, pp. X-CD, URL: www.X-cd.com.

[15] A. Al-Rawas and M. F. A. Goosen, Reactive soils, recent advances in characterization and treatment. London: Taylor \& Francis, 2006.

[16] R. Barthur, M. B. Jaksa, and P. W. Mitchell, "Design of residential footings built on expansive soil using probabilistic methods," in Proceedings of the 7th Australia New Zealand Conference on Geomechanics, Adelaide, 1996, pp. 369374.

[17] B. R. Phanikumar and N. Ramachandra Rao, "Increasing pull-out capacity of granular pile anchors in reactive soils using base geosynthetics," Canadian Geotechnical Journal, vol. 37, pp. 870-881, 2000.

[18] B. R. Phanikumar, A. Srirama Rao, and K. Suresh, "Field behaviour of granular pile-anchors in reactive soils," Ground Improvement, vol. 161, pp. 199-206, 2008.

[19] R. S. Sharma, B. R. Phanikumar, and G. Nagendra, "Compressive load response of granular piles reinforced with geogrids," Canadian Geotechnical Journal, vol. 41, pp. 187-192, 2004.

[20] A. Ismail and M. A. Shahin, "Numerical modelling of ground pile-anchor foundations (GPAF) in reactive soils," International Journal of Geotechnical Engineering, vol. 6, pp. 149-156, 2012.

[21] R. B. Brinkgreve and W. Broere, PLAXIS 2D manual, Version 9.0. The Netherland: Delft University of Technology and PLAXIS, 2008.

[22] T. Schanz, P. A. Vermeer, and P. G. Bonnier, "The hardening-soil model: formulation and verification," in Beyond 2000 in Computational Geotechnics, R. B. J. Brinkgreve, Ed., ed Rotterdam: Balkema, 1999, pp. 281-290.

[23] R. B. Brinkgreve and W. Broere, PLAXIS 3D foundation manual, Version 2.2. The Netherland: Delft University of Technology and PLAXIS, 2008.

[24] M. A. Ismail and M. A. Shahin, "Finite element modeling of innovative shallow foundation system for reactive soils," International Journal of GEOMAT, vol. 1, pp. 2186-2982, 2011.

[25] M. W. Bari and M. A. Shahin, "Probabilistic design of ground improvement by vertical drains for soil of spatially variable coefficient of consolidation," Geotextiles and Geomembranes, vol. 42, pp. 1-14, 2014.

[26] M. W. Bari and M. A. Shahin, "Three-dimensional finite element analysis of spatially variable PVD improved-ground," GeoRisk: Assessment and Management of Risk for Engineered Systems and Geohazards, vol. 9, pp. 37-48, 2015.

[27] M. W. Bari and M. A. Shahin, "Reliability-based semi-analytical design method for ground improvement by PVDs considering inherent (spatial) variability of soil," Computers and Geotechnics, vol. 67, pp. 121-134, 2015.

[28] M. W. Bari, M. A. Shahin, and H. R. Nikraz, "Effects of soil spatial variability on axisymmetric versus plane strain analyses of ground improvement by prefabricated vertical drains," International Journal of Geotechnical Engineering, vol. 6, pp. 139-147, 2012.

[29] M. W. Bari, M. A. Shahin, and H. R. Nikraz, "Probabilistic analysis of soil consolidation via prefabricated vertical drains," International Journal of Geomechanics, vol. 13, pp. 877-881, 2013.

[30] P. K. Lee, K. H. Xie, and Y. K. Cheung, "A study on one-dimensional consolidation of layered systems," International Journal of Numerical and Analytical Methods in Geomechanics, vol. 16, pp. 815-831, 1992.

[31] I. C. Pyrah, "One-dimensional consolidation of layered soils," Geotechnique, vol. 46, pp. 555-560, 1996. 
[32] G. B. Baecher and J. T. Christian, Reliability and statistics in geotechnical engineering. West Sussex, UK: John Wiley \& Sons, 2003.

[33] A. Fenton and E. H. Vanmarcke, "Simulation of random fields via local average subdivision," Journal of Engineering Mechanics, vol. 116, pp. 1733-1749, 1990.

[34] E. H. Vanmarcke, Random fields: analysis and synthesis. Massachusetts: The MIT Press, 1983.

[35] M. D. Duncan, "Factors of safety and reliability in geotechnical engineering," Journal of Geotechnical and Geoenvironmental Engineering, vol. 126, pp. 307-316, 2000.

[36] F. H. Kulhawy, M. J. S. Roth, and M. D. Grigoriu, "Some statistical evaluations of geotechnical properties," in Proceedings of the 6th International Conference on Applied Statistical Problems in Civil Engineering (ICASP 6), Mexico City, 1991, pp. 705-712.

[37] I. K. Lee, W. White, and O. G. Ingles, Geotechnical Engineering. Boston: Pitman Publishing Inc., 1983.

[38] R. J. Hoeksema and P. K. Kitanidis, "Analysis of the spatial structure of properties of selected aquifers," Water Resources Research, vol. 21, pp. 563-572, 1985.

[39] E. A. Sudicky, "A natural gradient experiment on solute transport in a sand aquifer: Spatial variability of hydraulic conductivity and its role in the dispersion process," Water Resources Research, vol. 22, pp. 2069-2083, 1986.

[40] M. Badaoui, A. Nour, A. Slimani, and M. K. Berrah, "Consolidation statistics investigation via thin layer method analysis," Transport in Porous Media, vol. 67, pp. 69-91, 2007.

[41] D. V. Griffiths and G. A. Fenton, "Seepage beneath water retaining structures founded on spatially random soil," Géotechnique, vol. 43, pp. 577-587, 1993.

[42] J. Huang, D. V. Griffiths, and G. A. Fenton, "Probabilistic analysis of coupled soil consolidation," Journal of Geotechnical and Geoenvironmental Engineering, vol. 136, pp. 417-430, 2010.

[43] G. A. Fenton and D. V. Griffiths, Risk assessment in geotechnical engineering. New Jersey: John Wiley and Sons, 2008.

[44] J. P. Carter and N. P. Balaam, "Program AFENA - A general finite element algorithm: Users' Manual," Centre for Geotechnical Research, University of Sydney, 1995.

[45] M. A. Biot, "General theory of three-dimensional consolidation," Journal of Applied Physics, vol. 12, pp. 155-164, 1941.

[46] S. Hansbo, "Consolidation of fine-grained soils by prefabricated drains," presented at the Proceedings of the 10th International Conference on Soil Mechanics and Foundation Engineering, Stockholm, Sweden, 1981.

[47] L. W. Gelhar, Stochastic Subsurface Hydrology. Englewood Cliffs, New Jersey: Prentice Hall, 1993.

[48] G. Dagan, Flow and transport in porous media. New York: Springer, 1989.

[49] M. A. Shahin and M. W. Bari, "Modeling of ground improvement by prefabricated vertical drains in highly variable soils," in Proceedings of the International Conference on Ground Improevement and Ground Control, Wollongong, Australia, 2012, pp. 321-335. 